San Jose State University

SJSU ScholarWorks

Master's Theses

Master's Theses and Graduate Research

Spring 2012

\title{
A Comparison of Two Versions of Modified Mercalli Intensity for Earthquake Exposure Assessment
}

Jamie Lynne Ratliff

San Jose State University

Follow this and additional works at: https://scholarworks.sjsu.edu/etd_theses

\section{Recommended Citation}

Ratliff, Jamie Lynne, "A Comparison of Two Versions of Modified Mercalli Intensity for Earthquake Exposure Assessment" (2012). Master's Theses. 4164.

DOI: https://doi.org/10.31979/etd.wbzz-g2ww

https://scholarworks.sjsu.edu/etd_theses/4164

This Thesis is brought to you for free and open access by the Master's Theses and Graduate Research at SJSU ScholarWorks. It has been accepted for inclusion in Master's Theses by an authorized administrator of SJSU ScholarWorks. For more information, please contact scholarworks@sjsu.edu. 


\title{
A COMPARISON OF TWO VERSIONS OF MODIFIED MERCALLI INTENSITY FOR EARTHQUAKE EXPOSURE ASSESSMENT
}

\author{
A Thesis \\ Presented to \\ The Faculty of the Department of Geography \\ San José State University \\ In Partial Fulfillment \\ of the Requirements for the Degree \\ Master of Arts
}

by

Jamie L. Ratliff

May 2012 
(C) 2012

Jamie L. Ratliff

ALL RIGHTS RESERVED 
The Designated Thesis Committee Approves the Thesis Titled

\title{
A COMPARISON OF TWO VERSIONS OF MODIFIED MERCALLI INTENSITY FOR EARTHQUAKE EXPOSURE ASSESSMENT
}

\section{by}

Jamie L. Ratliff

\author{
APPROVED FOR THE DEPARTMENT OF GEOGRAPHY \\ SAN JOSÉ STATE UNIVERSITY \\ May 2012 \\ Dr. Richard Taketa Department of Geography \\ Dr. M. Kathryn Davis Department of Geography \\ Nathan Wood, Ph.D. $\quad$ U.S. Geological Survey
}




\section{ABSTRACT \\ A COMPARISON OF TWO VERSIONS OF MODIFIED MERCALLI INTENSITY FOR EARTHQUAKE EXPOSURE ASSESSMENT}

by Jamie L. Ratliff

The U.S. Geological Survey conducted an earthquake exposure assessment for the State of Washington using peak ground acceleration (PGA) shaking from the USGS ShakeMap Project grouped to approximate Modified Mercalli Intensity (MMI) classes. Since ShakeMap datasets also have data representing official MMI classes, a companion exposure assessment was performed to determine whether MMI-grouped PGA data and official MMI data are interchangeable. Along with the exposure assessment, a spatial sampling process was used to further check how MMI-grouped PGA and official MMI data compared. Results indicated that significant variations existed spatially between the two ShakeMap datasets; generalizations by ShakeMap in creating their publically available data as well as the formulae ShakeMap's model uses to calculate MMI from PGA and peak ground velocity generally explain the variations. Though the two datasets differ significantly spatially, these results simply demonstrated that MMI-grouped PGA and official MMI are not interchangeable and did not identify one dataset as more appropriate than another for exposure assessments. 


\section{ACKNOWLEDGEMENTS}

This manuscript would never have come to fruition without the support (both intellectual and moral) of various people. Countless thanks go out to my family and friends for being supportive through the entire thesis process, and to my professors for their patience with the development and implementation of this research. My sincerest gratitude extends to my advisor Dr. Richard Taketa as well as Dr. M. Kathryn Davis for representing San José State University and the Department of Geography on my thesis committee. Finally, I want to express my sincere thanks to my coworkers at the U.S. Geological Survey, particularly thesis committee member Nathan Wood, for their encouragement, support, and inspiration for this research. None of this would have come to pass without the input and encouragement all these people provided. 


\section{TABLE OF CONTENTS}

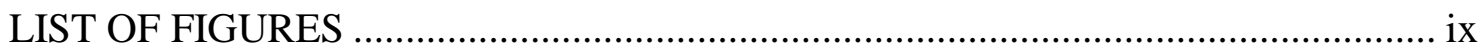

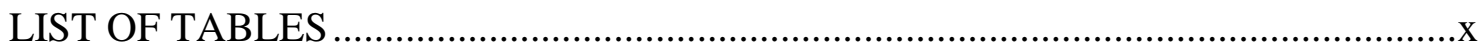

INTRODUCTION: VULNERABILITY, EXPOSURE, AND SOCIETY ........................1

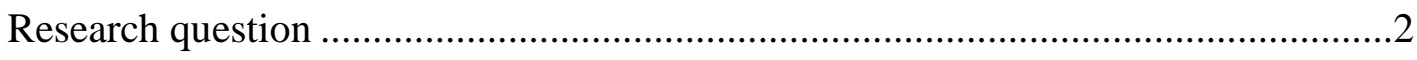

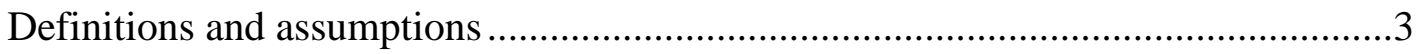

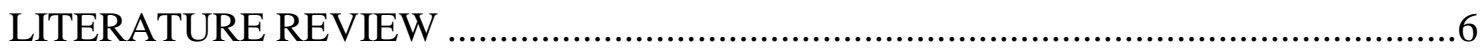

Vulnerability as a component of risk ................................................................

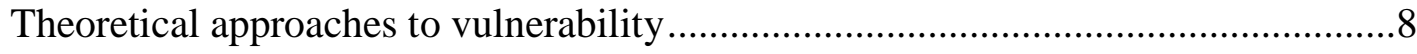

Additional aspects of vulnerability: indicators .......................................................11

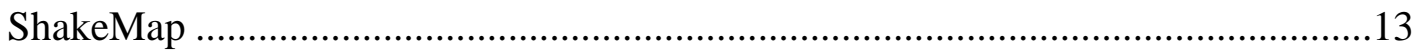

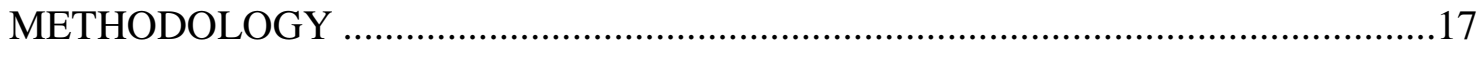

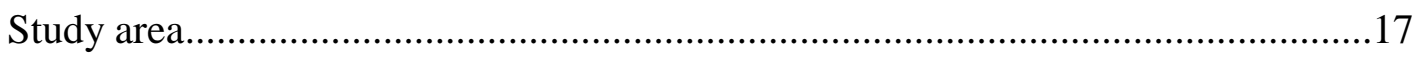

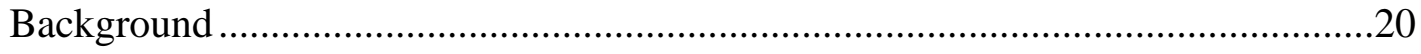

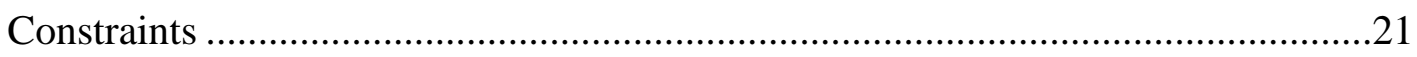

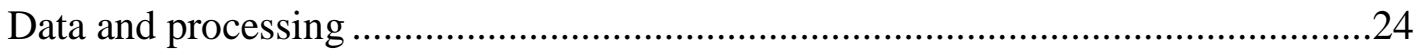

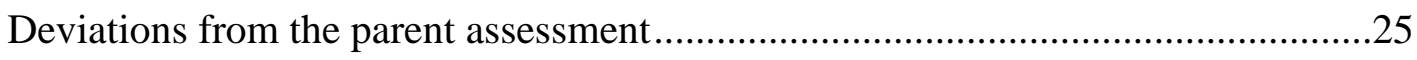

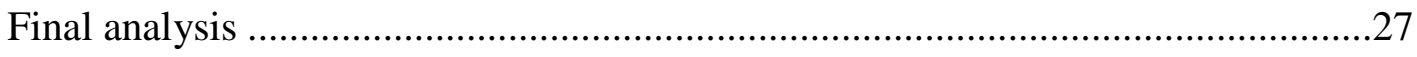

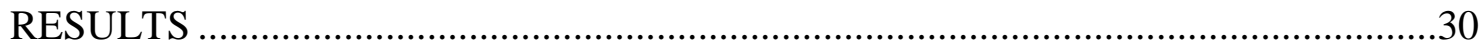

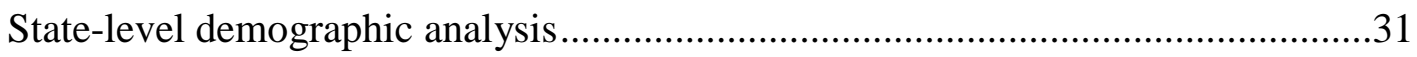

County-level demographic analysis ......................................................................34

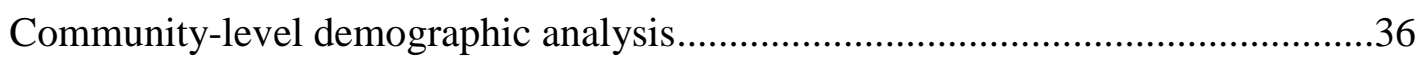




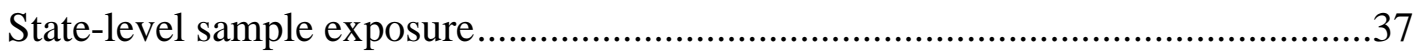

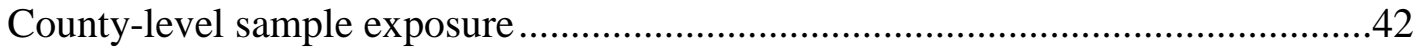

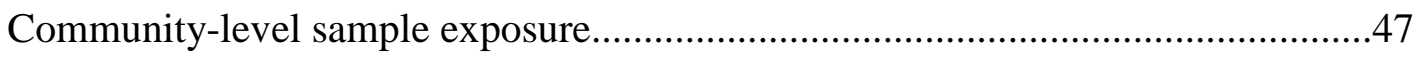

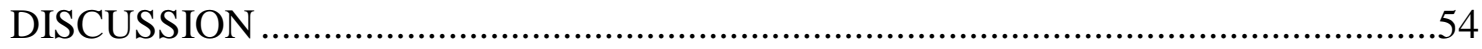

ShakeMap and spatial differences .........................................................5

Issues

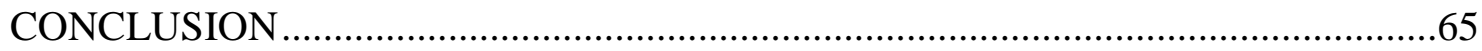

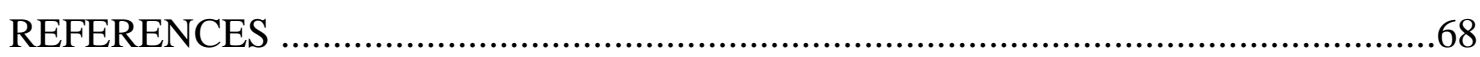

APPENDIX 1. The Modified Mercalli Intensity Scale ..........................................71

APPENDIX 2. Selected ShakeMap earthquakes — basic statistics ............................72

APPENDIX 3. MMI-grouped PGA vs. MMI population exposure correlations ...........73

State MMI class exposure correlations ...................................................73

King County MMI class exposure correlations ..........................................74

Thurston County MMI class exposure correlations......................................75

Seattle city MMI class exposure correlations ............................................76

Olympia city MMI class exposure correlations .........................................77

APPENDIX 4. Inconsistency index frequency distributions ..................................78

APPENDIX 5. Detailed statistics for spatial analyses ..........................................

State-level MMI-grouped PGA descriptive statistics by earthquake.................79

State-level MMI descriptive statistics by earthquake ...................................79

County-level MMI-grouped PGA descriptive statistics by earthquake:

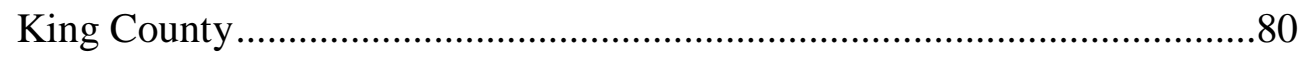


County-level MMI descriptive statistics by earthquake: King County

County-level MMI-grouped PGA descriptive statistics by earthquake:

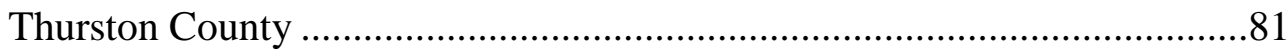

County-level MMI descriptive statistics by earthquake: Thurston County ........81

Community-level MMI-grouped PGA descriptive statistics by earthquake:

Seattle.

Community-level MMI descriptive statistics by earthquake: Seattle

Community-level MMI-grouped PGA descriptive statistics by earthquake:

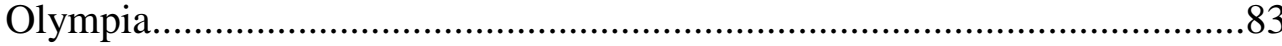

Community-level MMI descriptive statistics by earthquake: Olympia.............83

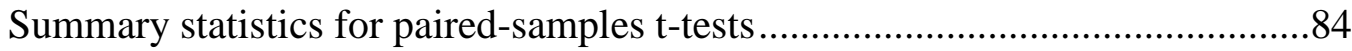




\section{LIST OF FIGURES}

Figure 1. The interaction between hazard, vulnerability, and risk ..............................

Figure 2. Study areas (state: Washington; county: King, Thurston; community:

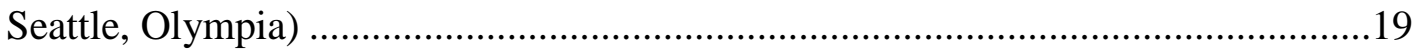

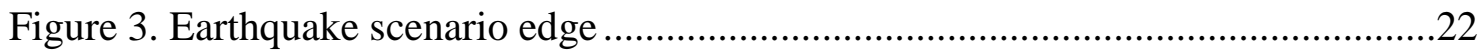

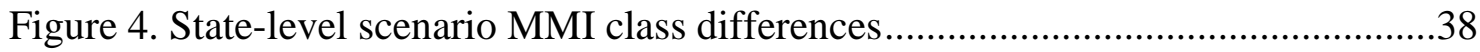

Figure 5. State-level spatial inconsistency index .............................................40

Figure 6. State-level inconsistency/count ratio index .........................................41

Figure 7. County-level scenario MMI class differences ..........................................45

Figure 8. County-level spatial inconsistency index ............................................46

Figure 9. County-level inconsistency/count ratio index .........................................46

Figure 10. Community-level scenario MMI class differences..................................48

Figure 11. Community-level spatial inconsistency index .....................................51

Figure 12. Community-level inconsistency/count ratio index ..................................51

Figure 13. Variations between original and new Cascadia and Seattle earthquake

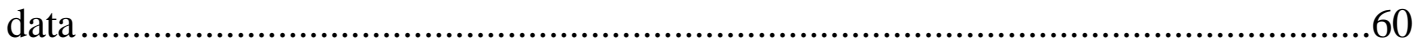

Figure 14. Polygon overlap data error in Cascadia Earthquake MMI data ..................61

Figure 15. Boundary discrepancy in projected PGA and MMI ShakeMap data ...........63 


\section{LIST OF TABLES}

Table 1. Processed Washington State ShakeMap earthquakes ..................................23

Table 2. Lake Creek MMI-grouped PGA total population exposure comparison..........27

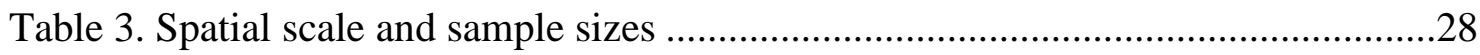

Table 4. Correlation coefficients for MMI-grouped PGA and MMI for exposed population

Table 5. Correlation coefficients for MMI-grouped PGA and MMI for exposed occupied housing units.

Table 6. Difference between correlation coefficients for MMI-grouped PGA and MMI for exposed population and exposed occupied housing units

Table 7. State population exposures for SWIF and SWIF Southeast earthquakes .34

Table 8. King County population exposures for SWIF and SWIF Southeast earthquakes

Table 9. Thurston County population exposures for SWIF and SWIF Southeast earthquakes

Table 10. Seattle city population exposures for SWIF and SWIF Southeast earthquakes

Table 11. Olympia city population exposures for SWIF and SWIF Southeast earthquakes

Table 12. State-level paired-sample t-test statistics

Table 13. County-level paired-sample t-test statistics

Table 14. Community-level paired-sample t-test statistics..... 
Table 15. Summary of number and percentage of paired population exposure results from twelve earthquakes by scale.....................................................55

Table 16. Summary of number and percentage of unpaired population exposure results from twelve earthquakes by scale.....................................................55

Table 17. Summary of exposure occurrence percentages from twelve earthquakes by MMI class and scale...... .56 


\section{Introduction: Vulnerability, Exposure, and Society}

Former Department of Homeland Security Secretary Michael Chertoff testified in a post-Hurricane Katrina disaster response hearing before the House of Representatives in February 2006:

Any county or locality that sits and waits for FEMA [Federal Emergency Management Agency] to come and give it a plan is going to find itself under water. Emergency planning has to begin at the local level, and if there are areas where there are missing capabilities, that is the kind of thing that we can help with and the State has to help with. (House of Representatives Committee, 2006, p. 33)

Local-level resources are not necessarily sufficient to cope with a large-scale emergency response. Ideally, response would be a cooperative effort between local, state, and federal agencies as well as the public, private, and voluntary sectors. Vulnerability analyses can provide bases for developing multi-scale response plans; these plans can help minimize the time between a disaster and emergency response for the stricken region.

One aspect of a vulnerability analysis is an exposure assessment. Whereas vulnerability is the overall susceptibility (including social, natural, economic, and other characteristics) of a region to a disaster (Wisner et al., 2003), exposure is specifically the enumeration and percentage of assets (land, businesses, people, etc.) within a hazard zone (Wood, 2009). For example, the exposure of a small coastal community to a hurricane could be comprehensive - all 750 residents experience the hurricane-but the community's characteristics would define overall vulnerability. A young, industrial, and well-connected community could be more resilient and therefore less vulnerable than an older, tourism-based, minimally-connected community. The latter community's socio- 
economic characteristics would likely make the community less resilient and more vulnerable, even if all other community characteristics were the same in the former community.

\section{Research question}

This thesis answers the question of whether two related ground-shaking datasets from the U.S. Geological Survey (USGS) Earthquake Hazards Program’s ShakeMap Project can be used interchangeably for exposure counts as part of an earthquake vulnerability assessment. The ShakeMap datasets of interest are peak ground acceleration (PGA) and Modified Mercalli Intensity (MMI). PGA data were grouped into approximations of MMI based on the chart in Appendix 1 and then compared to the official MMI data to determine interchangeability. Three different scales were evaluated: Washington at the state level, King County and Thurston County at the county level, and the cities of Seattle and Olympia at the community level. This evaluation was conducted at the community (or local) level as well as the state and regional level to potentially demonstrate how scale impacts exposure counts and vulnerability assessments.

Two different approaches are used to answer the research question. First, a basic socioeconomic hazard exposure assessment was completed following the process employed by Wood and colleagues (Wood \& Soulard, 2009; Frazier, Wood, Yarnal, \& Bauer, 2010; Wood \& Ratliff, 2011). Second, a representative sample of each study region was extracted to compare how frequently spatial differences between PGA and MMI ShakeMap datasets occur. The results of both approaches were analyzed to formally answer if PGA and MMI ShakeMap datasets were interchangeable. 


\section{Definitions and assumptions}

Some definitions need to be established to place the research ideas in context. A hazard refers to any natural or anthropogenic event which could endanger human life and property. This differs from the Federal Emergency Management Agency (FEMA) definition of hazard as "an emergency or disaster resulting from a natural disaster or an accidental or man-caused event" (FEMA, 2010). FEMA's definition of hazard refers to common hazards (hurricane, landslide, earthquake, tsunami, etc.) as well as more uncommon hazards (epidemic disease, terrorism, etc.). The specific hazard of interest for this analysis was the earthquake, a mass earth movement where two conflicting segments of the Earth's crust slip and release energy in the form of seismic waves. In contrast with hazard, a disaster is the significant damage (structural, economic, or anthropogenic) resulting from a hazard. FEMA (2010) defines a natural disaster as:

any hurricane, tornado, storm, flood, high water, wind-driven water, tidal wave, tsunami, earthquake, volcanic eruption, landslide, mudslide, snowstorm, drought, fire, or other catastrophe in any part of the United States which causes, or which may cause; substantial damage or injury to civilian property or persons.

A disaster is the aftermath of a hazard's occurrence relative to society: a wildfire in vast grasslands with little socioeconomic importance may not be a disaster since the fire does not directly impact humans or human-required resources/capital. This point emphasizes the idea that a disaster exists only if people decide it exists: a disaster is socially constructed (Bankoff et al., 2004).

Having identified the earthquake as the hazard of interest in this research, some definitions describing shaking (how earthquakes are represented) are also important to note. The purpose of the comparison between the PGA and MMI ShakeMap datasets 
was to determine if they are interchangeable. This is in part because PGA represents instrumental shaking and MMI represents perceived shaking. Instrumental shaking is shaking derived from readings collected by seismometers both on and beneath the Earth's surface. Perceived shaking, on the other hand, is shaking based on what people believe they feel (the shaking intensity is defined by how much shaking people decide they see or sense). Instrumental shaking may be more representative of the actual shaking that occurred at any particular location, but perceived shaking is more easily understood by emergency managers and responders. Perceived shaking is thus potentially a more useful representation of an earthquake than instrumental shaking.

Along with the definitions that need to be established for this research, some assumptions must be laid out to understand why analyses are being performed in the manner they are. One assumption being made in this assessment is that the only data options available for the analysis are PGA and MMI. Additional datasets are available from ShakeMap, including peak ground velocity; this dataset also may be grouped into MMI classes as demonstrated by Wald, Quitoriano, Heaton, \& Kanamori (1999). Another assumption present throughout this analysis is that significant differences exist spatially between PGA grouped into MMI and official MMI datasets. The final assumption being made is that spatial scale will have a significant effect on the differences between the PGA and MMI datasets. The second and third assumptions of spatial and scale difference significance are the two main research hypotheses for the analysis. 
Seven sections follow the introduction in this manuscript. The literature review provides background information on vulnerability, ShakeMap, and how MMI and PGA differ in ShakeMap. A methodology section details the study area and processing that was performed for the research. The results describe the various data outputs (exposureand sample-based) and what they suggest about the interchangeability of the ShakeMap MMI and PGA datasets. Issues which presented themselves during the research process and potential implications of the results comprise the discussion. Concluding remarks summarizing the research end the body of the document. Finally, a bibliography and five appendices supplement the paper. 


\section{Literature Review}

A brief review of a few key topics related to exposure and ShakeMap earthquake data needs to be completed to understand the research background. This section's first topic is an introduction to the concepts of exposure, vulnerability, and, peripherally, risk. The ShakeMap section comprising the latter half of this review will cover both the ShakeMap project itself (formulae, outputs, etc.) and the differences between PGA and MMI shaking as recognized by ShakeMap.

\section{Vulnerability as a component of risk}

Vulnerability is a complex topic with applications in many areas of society. One

of these areas relates to natural hazards and the disasters that accompany them. As noted earlier, hazards are simply events which could endanger people or property and disasters are the outcomes of hazards which actually result in significant loss of property or life (Alcántara-Ayala, 2002; Uitto, 1998; FEMA, 2010). Vulnerability in this context is the measure of how damaging a particular hazard or set of hazards could be to a population (community, county, country, etc.) due to pre-event socioeconomic conditions. Figure 1 illustrates how hazard and vulnerability interact to determine risk.

Various definitions exist regarding vulnerability, with definitions changing depending on the discipline. Social scientists and physical scientists see vulnerability very differently: social science definitions of vulnerability are generally explanatory and physical science definitions are generally descriptive (Füssel, 2007). The specific definition of vulnerability also varies within the same discipline depending on the situation (Füssel, 2007; Delor \& Hubert, 2000). Though the vulnerability definition 
varies both between and within disciplines, a general consensus suggests that vulnerability is:

the physical and socioeconomic factors that influence the degree to which an individual, community, or system is threatened and is often expressed as a function of an object's or system's exposure, sensitivity, and adaptive capacity to a hazard. (Frazier, Wood, Yarnal, \& Bauer, 2010, p. 491)

A second, more succinct definition of vulnerability is provided by Birkmann \& Wisner (2006): vulnerability, regardless of the discipline, represents the "internal side of risk" or "an intrinsic characteristic of a system" (p. 10).

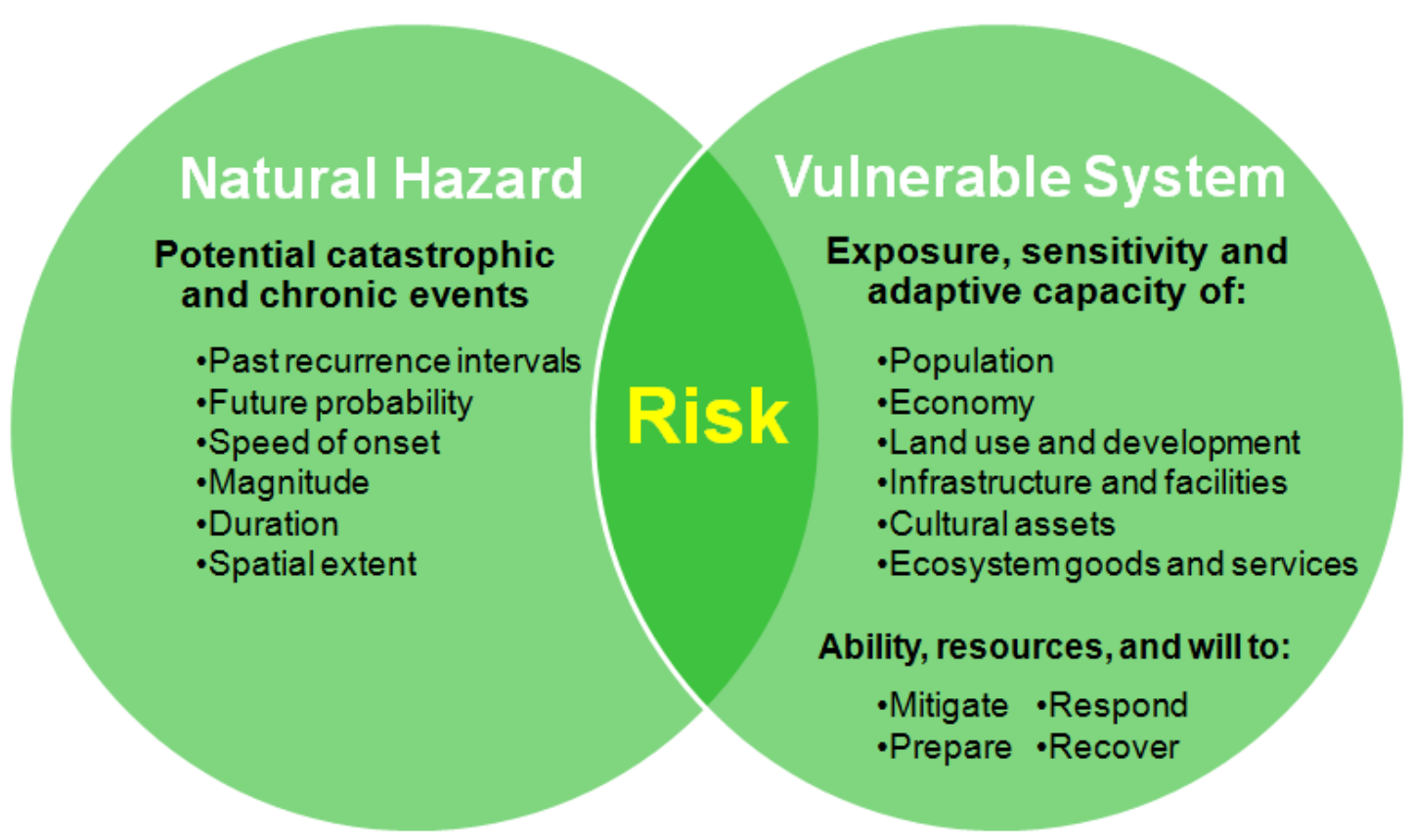

Figure 1. The interaction between hazard, vulnerability, and risk. A natural hazard and a system's vulnerability overlap to determine that system's risk (reproduced with permission from Wood, 2011).

Vulnerability is further broken down into two or three components depending on the scientist. In general, vulnerability is composed of at least the following two categories: exposure and resistance/resilience (Linnekamp, Koedam, \& Baud, 2011). 
Exposure, according to Linnekamp et al., is a result of the physical and socioeconomic characteristics of a place or group of people. Cross (2001) further defines physical exposure as the likelihood of an event occurring combined with the proportion of the community affected by the event. Resistance or resilience is the ability of a place or group to recover from a disaster, with resistance being the reduction of initial effects from the event and resilience being the recovery time following the event. Birkmann \& Wisner (2006), rather than having listed resistance/resilience as the second component of vulnerability, stated that in vulnerability's broadest sense susceptibility is exposure's counterpart. The authors also discussed resilience as a component of vulnerability, demonstrating that the specific vulnerability definition will determine what components are required for an assessment.

\section{Theoretical approaches to vulnerability}

McLaughlin \& Dietz (2008) found during a literature search that five major theoretical classes or approaches exist regarding vulnerability. The five theoretical vulnerability approaches were: biophysical, human ecological, political economy, constructivist, and political ecology. Each of these approaches had both strengths and weaknesses. The authors concluded that disparate research areas needed to be more integrated for a more comprehensive sense of vulnerability; this integration was being

prevented by existing nominalist and essentialist practices (p. 99-100). Each of the five theoretical vulnerability approaches is detailed below.

Biophysical vulnerability was concerned purely with the characteristics of the biophysical world as an indicator of human vulnerability. This was the most common 
theoretical approach used when assessing vulnerability to climate change and other natural hazards (McLaughlin \& Dietz, 2008, p. 100). An example of this would be using marginal agricultural land assessments established based on soil characteristics to help determine human vulnerability to climate change. Biophysical vulnerability did not take human factors (economics, society, etc.) into consideration, and as such was limited in its overall viability. The relative ease with which a biophysical assessment could be conducted was identified as a major reason for using this method; the difficulty with which human behavior could be predicted was another reason to use the biophysical approach since human behavior was not considered.

The human ecological approach to vulnerability was noted as the first to attempt to incorporate the human/social component into vulnerability assessment. This approach used the interaction between the ecological (environmental behavior) and human response to the ecological to refine vulnerability (McLaughlin \& Dietz, 2008, p. 101). Though the addition of human behavior and response was incorporated into human ecological theory, the attempt restricted how society behaved in analyses. More recent applications of the human ecology method tried to remove this constraint but were only marginally successful.

Unlike the biophysical and human ecology approaches to vulnerability, the political economy approach defined vulnerability almost exclusively as the relationship between humanity and humanity's economic/political positioning in society. Though the environment was considered in the political economy approach, in practice any environmental effect was contingent on the economic/political practices impacting it 
(McLaughlin \& Dietz, 2008, p. 102). The political economy approach also removed the unique impact culture had on overall vulnerability.

The constructivist perspective on vulnerability stated that human agency and culture defined the vulnerability of a society. One example of human agency or culture affecting vulnerability would be religion: devout religious people may potentially leave fate to chance, not retrofitting homes in case of an earthquake because God would decide whether houses would be damaged or not regardless of human intervention. This approach also questioned the definition of risk by emphasizing that perceptions on gender, race, and age all had an influence on the idea of risk (McLaughlin \& Dietz, 2008, p. 103). Constructivists, though they added the culture component necessary for a more complete vulnerability definition, had so dedicated themselves to the idea that every aspect of vulnerability was simply perception that broad, universal applications were extremely difficult.

The last vulnerability approach identified by McLaughlin \& Dietz was the political ecology theory. Like the political economy approach, the effects of policy and economics played a huge part in defining vulnerability in the political ecology approach. The political ecology approach filled in the gap between the environment and the anthropogenic that was so problematic in the political economy approach by allowing the environment to impact policy and economics rather than just the other way around (2008, p. 103). Political ecology did no better than any of the other theories mentioned at successfully combining all important aspects of vulnerability: environment, economy, policy, culture, and history. 
Each of the above theories on vulnerability has an impact on how scientists conduct research. McLaughlin \& Dietz noted that no one of the current theories on vulnerability was complete. Not considering social impacts ignores a key aspect of vulnerability, but focusing too narrowly on social impacts can obscure the important part economics and the environment play in vulnerability as well. A balance must be struck between the various pieces comprising vulnerability to efficiently and effectively evaluate the phenomenon. Exposure plays into all vulnerability theories by providing a base for assessing vulnerability—without exposed populations and assets, no vulnerability would exist.

\section{Additional aspects of vulnerability: indicators}

The extent of a population's vulnerability depends on the hazard of interest as well as the characteristics of the population (Cross, 2001; Wisner et al., 2004). A community's vulnerability to a hurricane or other large-scale hazard is different than the same community's vulnerability to a more localized hazard like a landslide. The scale of the hazard plays a part in the population's vulnerability, as does the demographic characteristics of the population. For example, a retirement community with a large percentage of its population aged over 65 would be more vulnerable to hazards with a small window of reaction time available (e.g., a tsunami) than a college community with many of its residents aged between 18 and 24-the assumption is that an elderly population's reduced mobility would make them more vulnerable than a younger ablebodied population. Demographics are not the only indicator used to measure vulnerability, though: economics also provides some insight into vulnerability. 
In some cases community vulnerability can also be assessed by incorporating economic impacts into the analysis. The number and kinds of businesses established in a settlement potentially has an effect on vulnerability. For example, a large settlement with many and varied businesses may not be as vulnerable to a hazard as a small settlement reliant on a specific business (e.g., a mill for processing forestry products) since more diverse economies generally have greater adaptive capacity (adaptive capacity, however, is not necessarily correlated with vulnerability) (Williamson, Hesseln, \& Johnston, 2012). The likelihood of a settlement's economic base being devastated is potentially greater with a smaller or less diverse community than with a larger or more diverse community.

The effect of one spatial unit's vulnerability on other spatial units can also impact overall vulnerability. Scale and space should also be considered to fully appreciate a particular group's vulnerability. A severely damaged business-oriented community could impact a nearby residential community with few businesses by taking away part of that residential community's access to goods and services. For example, a small community with no hospital could be adversely affected if the nearest hospital in a neighboring community were damaged by a disaster. Connectivity between communities is also a concern since communities with multiple access routes could be more accessible to emergency responders after a disaster than communities with few access routes. Vulnerability is, in large part, a study in spatial relationships.

Vulnerability assessments can help to maximize capital investments in mitigation by providing focus for mitigation efforts. In At Risk: Natural hazards, people's vulnerability and disasters, Anderson (1990, cited in Wisner et al., 2004) commented that 
"it is cheaper in the long run (in economic, social and political senses of the word) to prevent or mitigate disasters than to fund recovery" (p. 34). Though this is not always the case since mitigating for all possible disasters could be prohibitively expensive, this is still a useful concept to keep in mind when considering hazards and hazard analysis. In the case of an earthquake, communities within a certain distance of a fault or fault zone could be targeted for mitigation investment if a vulnerability assessment determined they were more susceptible to earthquake damage (e.g., a community had critical facilities on loose, liquefaction-prone soils) than other communities. Focusing investment can help minimize post-disaster costs when carefully researched and selectively applied.

\section{ShakeMap}

One of the most common sources for earthquake shaking maps in digital format (both finished maps and GIS data for producing original maps) is the U.S. Geological Survey (USGS). The USGS Earthquake Hazards Program's ShakeMap Project web site provides a wide variety of earthquake data in digital form (USGS 2011b). ShakeMap uses seismic data collected from seismometers throughout the United States (and to a limited extent the rest of the world) to produce digital versions of earthquake shaking as well as generate scenarios based on known seismicity.

Data produced for an earthquake by ShakeMap includes: peak ground acceleration (PGA, reported as \%g); peak ground velocity ( $\mathrm{PGV}$, reported as $\mathrm{cm} / \mathrm{s})$; peak spectral acceleration (PSA, reported as $\% \mathrm{~g}$ ) for as many as three periods: $0.3,1.0$, and 3.0 seconds; and Modified Mercalli Intensity (MMI, reported as decimal intensity). Though all datasets from ShakeMap are produced using the same seismic information, MMI data 
are calculated by referring to PGA and PGV ShakeMap data: "[ $\mathrm{t}]$ he Instrumental Intensity Map is based on a combined regression of recorded peak acceleration and velocity amplitudes" (USGS, 2011a). ShakeMap MMI data approximate perceived shaking through an instrumental process, so regions where true perceived MMI values are unknown (e.g., unpopulated regions) still receive an MMI value in ShakeMap (Wald, Worden, Quitoriano, \& Pankow, 2006).

The ShakeMap Technical Manual stated that "[u]sing peak acceleration to estimate low intensities is intuitively consistent with the notion that lower $(<\mathrm{VI})$ intensities are assigned based on felt accounts, and people are more sensitive to ground acceleration than velocity" (Wald et al., 2006, p. 55). The authors continued by saying that "[w]ith more substantial damage (VII and greater), failure begins in more flexible structures, for which peak velocity is more indicative of failure" (Wald et al., 2006, p. 56). This revealed that no one instrumental record from an earthquake is sufficient in itself to interpolate MMI perceived shaking. ShakeMap's modeling process reflects this interpretation.

The general practice followed by ShakeMap to generate MMI zones is to use PGA from MMI I through MMI V, a combination of PGA and PGV for MMI classes V through VII and PGV for MMI classes VII and above (USGS, 2011a). MMI classes below V are less comparable to either PGA or PGV since they are more difficult to perceive, and classes exceeding IX (X to XII) blend together due to their high intensity. People are more sensitive to acceleration than velocity, so PGA approximates low MMI classes to correspond with the MMI scale's focus on human observation at lower classes. 
Structures are more susceptible to velocity than acceleration- $-\mathrm{PGV}$ is used from MMI VIII up since effects on structures better characterize higher MMI shaking classes (Wald, Quitoriano, Heaton, \& Kanamori, 1999). PGV is also more appropriate for approximating higher MMI classes since PGV continues to increase as shaking intensity increases while PGA eventually levels out (Wald et al., 1999).

Even knowing when PGA or PGV is more appropriate for using in place of MMI is not sufficient to assign an MMI class. PGA or PGV values must be converted to MMI using one of four formulae developed by looking at the relationship between MMI, PGA, and PGV for eight earthquakes in Southern California (Wald et. al., 1999). The four formulae in combination most completely approximate MMI using PGA and PGV:

$$
\begin{aligned}
& \text { (1) } \mathrm{I}_{\mathrm{mm}}=3.66 \log (\mathrm{PGA})-1.66 \text { when MMI } \mathrm{V}<=\mathrm{I}_{\mathrm{mm}}<=\mathrm{VIII} \text {; } \\
& \text { (2) } \mathrm{I}_{\mathrm{mm}}=3.47 \log (\mathrm{PGV})+2.35 \text { when MMI V }<=\mathrm{I}_{\mathrm{mm}}<=\mathrm{IX} \text {; } \\
& \text { (3) } \mathrm{I}_{\mathrm{mm}}=2.20 \log (\mathrm{PGA})+1.00 \text { when MMI } \mathrm{I}_{\mathrm{mm}}<\mathrm{V} \text { or; } \\
& \text { (4) } \mathrm{I}_{\mathrm{mm}}=2.10 \log (\mathrm{PGV})+3.40 \text { when MMI } \mathrm{I}_{\mathrm{mm}}<\mathrm{V}
\end{aligned}
$$

Formula (1) is used first to convert PGA (in $\mathrm{cm} / \mathrm{s}^{2}$ ) to MMI. If the resulting intensity value $\mathrm{I}_{\mathrm{mm}}$ is greater than VII then Formula (2) is used to convert PGV (in $\mathrm{cm} / \mathrm{s}$ ) to MMI instead. If the result from Formula (1) is less than V then the result from Formula (3) or (4) replaces Formula (1). In practice, Formula (3) is used rather than Formula (4) since PGA is more representative than PGV of low-level shaking intensity. These formulae reveal that even though a relationship between PGA and MMI has been established, the relationship is not perfect. Resulting MMI and PGA outputs from ShakeMap will therefore produce different results when doing a spatial exposure analysis. 
Having detailed some basics of vulnerability, how exposure relates to vulnerability, and how PGA and PGV relate to MMI in ShakeMap data, the next step is to establish the background and process followed for the research. The next section describes the exposure assessment process in detail and elaborates on the process used to compare the MMI-grouped PGA and official MMI ShakeMap datasets. These comparisons look at both the actual calculated exposures and spatial distributions determined by sampling. 


\section{Methodology}

The research methodology was based on the process used by Wood \& Ratliff to conduct their 2011 exposure assessment for the State of Washington. A description of the study areas for this research precedes the background of the reference USGS Washington exposure assessment. The methodology section concludes with a short discussion of the modifications being made to the original exposure assessment process to answer the research question: are MMI-grouped PGA ShakeMap data and official MMI ShakeMap data interchangeable in earthquake exposure assessments?

\section{Study Area}

The study area for this research consisted of five locations at three different spatial scales. One small-scale state-wide study area was examined, along with two midscale regional study areas and two large-scale local study areas. The small-scale state study area was the State of Washington. The two mid-scale county study areas were King County and Thurston County; King County was selected since this county is the most populous in Washington, and Thurston County was selected since the state capital is in the county. Thurston County was also selected since the county was severely impacted by the historical earthquake selected for the assessment. The two large-scale community study areas were the cities of Seattle and Olympia. Seattle is the most populous city in Washington, and Olympia is the state capital. Earthquakes have the potential to severely impact both communities, and damage to either community is likely to impact the remainder of the state. 
The State of Washington is bounded by the Pacific Ocean on the west, Oregon and Idaho to the south and east in the United States, and British Columbia to the north in Canada. The U.S. Bureau of the Census reported that Washington had a total population of 6,724,540 in 2010 and a total population of 5,894,121 in 2000. The increase in total population between 2000 and 2010 in Washington was 14.1\%. Covering an area of approximately 66,456 square miles, Washington had a 2010 population density of 101.2 people per square mile (U.S. Census Bureau, 2011f).

King County, located adjacent to the southeastern shore of Puget Sound in northwestern Washington, had a 2010 total population of 1,931,249 according to the Census. King County's 2000 population was 1,737,034, with an increase in population of $11.2 \%$ between 2000 and 2010 . The county's approximate area is 2,116 square miles with a 2010 population density of 912.9 people per square mile (U.S. Census Bureau, 2011a). In contrast, Thurston County (to the southwest of King County and touching the southern shore of Puget Sound) had a 2010 population of 252,264 compared to a 2000 population of 207,355 (an increase of 21.7\%). Thurston County presented a 2010 population density of 349.4 people per square mile of its 722 square mile area (U.S. Census Bureau, 2011d).

As the most populous city in both Washington and King County, Seattle's 2010 population was 608,660 . Seattle had a total population of 563,374 in 2000 according to the Census and a population increase of $8.0 \%$ between 2000 and 2010. Seattle covers 84 square miles abutting Puget Sound for a population density of 7,250.9 people per square mile in 2010 (U.S. Census Bureau, 2011c). The state capital of Olympia in Thurston 
County had a 2010 Census-derived population of 46,478 compared to a 2000 population of 42,514 (a percent increase of 9.3\%). The city covers 18 square miles with a population density of 2,608 people per square mile in 2010 (U.S. Census Bureau, 2011b).

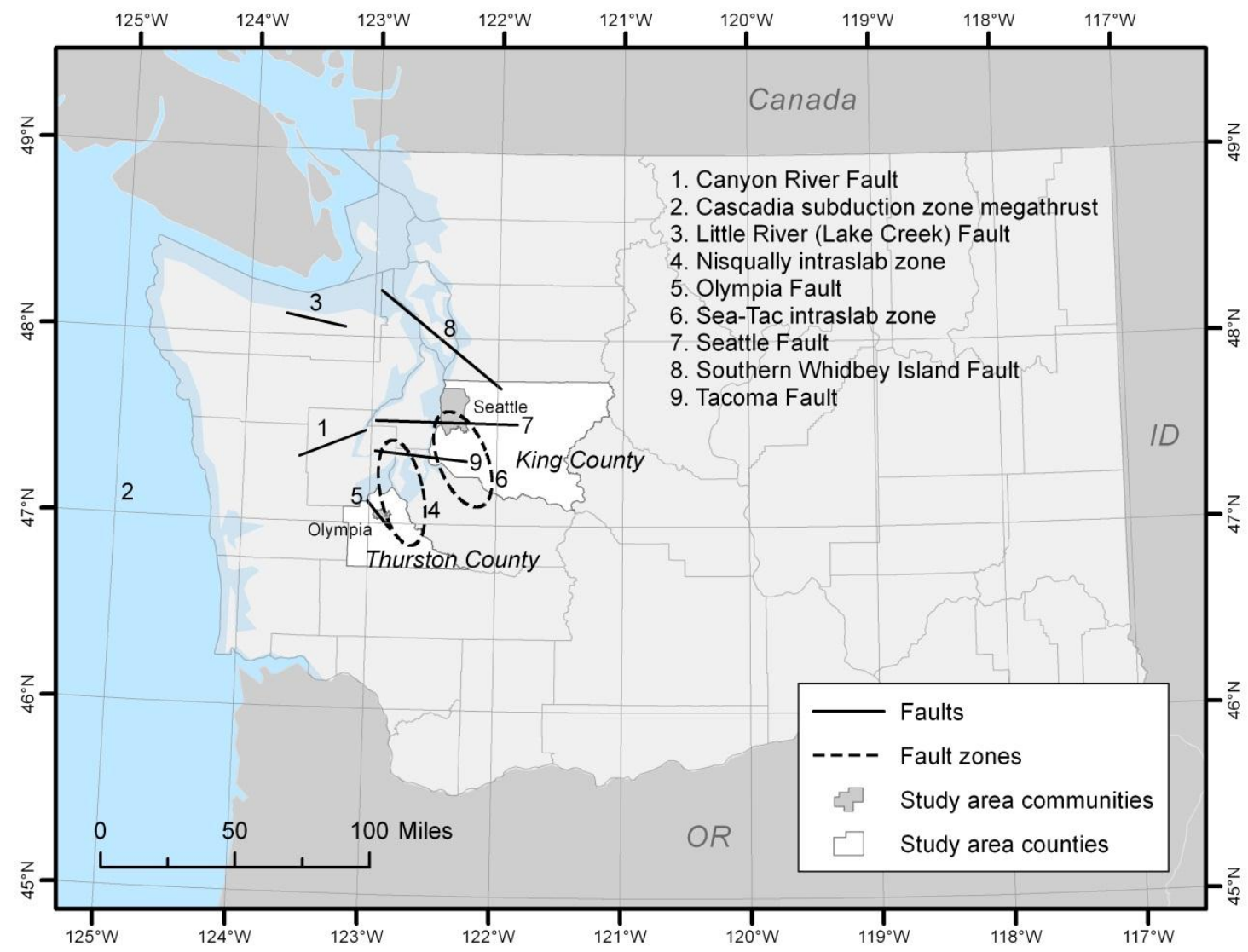

Figure 2. Study areas (state: Washington; county: King, Thurston; community: Seattle, Olympia). The fault/fault zones shown on the map are the origins for the twelve scenarios being used in the analysis. The Southern Whidbey Island Fault (SWIF), Nisqually intraslab zone, and Cascadia subduction zone megathrust each produced two earthquakes; all other faults/zones generated one earthquake.

Due to Washington's location along the Pacific Ocean, off-shore and inland earthquakes are a concern. The collision of the North American and Juan de Fuca plates off the state's western coast introduces the potential for off-shore subduction earthquakes as well as $25-100 \mathrm{~km}$ deep inland continental earthquakes; shallow ( $<30 \mathrm{~km}$ deep) inland 
earthquakes on numerous other faults are also common (Washington State Department of Natural Resources, 2012). All study areas analyzed in this project are shown in Figure 2. The faults and fault zones that serve as the twelve assessed earthquake origins are also shown in the map.

All five of the above study areas were assessed in this project to better understand the potential effects of using MMI data as opposed to MMI-grouped PGA data for exposure assessment analyses. The expectation was that as areas become smaller (as scale becomes larger), MMI and PGA will have different impacts on the overall distribution between MMI classes. Specifically, the assumption was that as scale changes from smaller to larger the overall impact of the type of MMI data used would shrink.

\section{Background}

The analysis conducted by Wood \& Ratliff (2011) was a collaboration between the USGS and the State of Washington Emergency Management Division (WEMD). WEMD identified twenty earthquake scenarios which were then generated by ShakeMap and loaded into the USGS ShakeMap digital archive. These ShakeMap data were selected for their compatibility with HAZUS-MH (a FEMA application WEMD used for loss estimation (FEMA, 2012)) as well as a traditional geographic information system (GIS) used for USGS's exposure assessment.

Data downloaded from the ShakeMap web site have up to six components available in vector polygon and raster grid format: Modified Mercalli Intensity (MMI), peak horizontal ground acceleration (PGA), peak horizontal ground velocity (PGV), and at least one of three peak spectral acceleration (PSA) spectral response periods: 0.3- 
second spectral response (PSA03), 1-second spectral response (PSA10), and 3-second spectral response (PSA30). For the exposure assessment, PGA polygon data were used and reclassified to approximate MMI classes. WEMD used PGA data for its HAZUSMH analysis, but MMI-represented perceived shaking would be clearer to emergency managers and decision-makers. Using MMI-grouped PGA data allowed the exposure assessment to remain consistent with WEMD's HAZUS-MH analyses while still representing the data in a clear way for emergency managers and decision-makers. Appendix 1 shows the comparison between MMI and PGA values for the ShakeMap data analyzed along with descriptions of MMI shaking intensity characteristics.

MMI classes V through IX were selected through an agreement with WEMD to be the classes the exposure assessment would describe. An MMI class of V generally suggests shaking severe enough to begin to cause non-structural property damage (e.g., dishes breaking) and become a potential disaster. Though a small amount of data were available for MMI class IV, the minimum MMI class of V was selected to allow a better sense of where emergency money may need to be spent since potential non-structural property damages are important to consider along with potential loss of life.

\section{Constraints}

The data acquired from ShakeMap had various constraints to account for when using the data for the exposure assessment. One of the constraints was that the spatial extent of the MMI V class was far greater than any other analyzed MMI classes; many communities reported complete potential exposure constrained to only the MMI V class. In addition, an explicit boundary was established prior to running the ShakeMap model to 
create the various shaking components. This pre-determined scenario boundary excluded some relevant potential shaking zones. Figure 3 illustrates one example of this boundary.

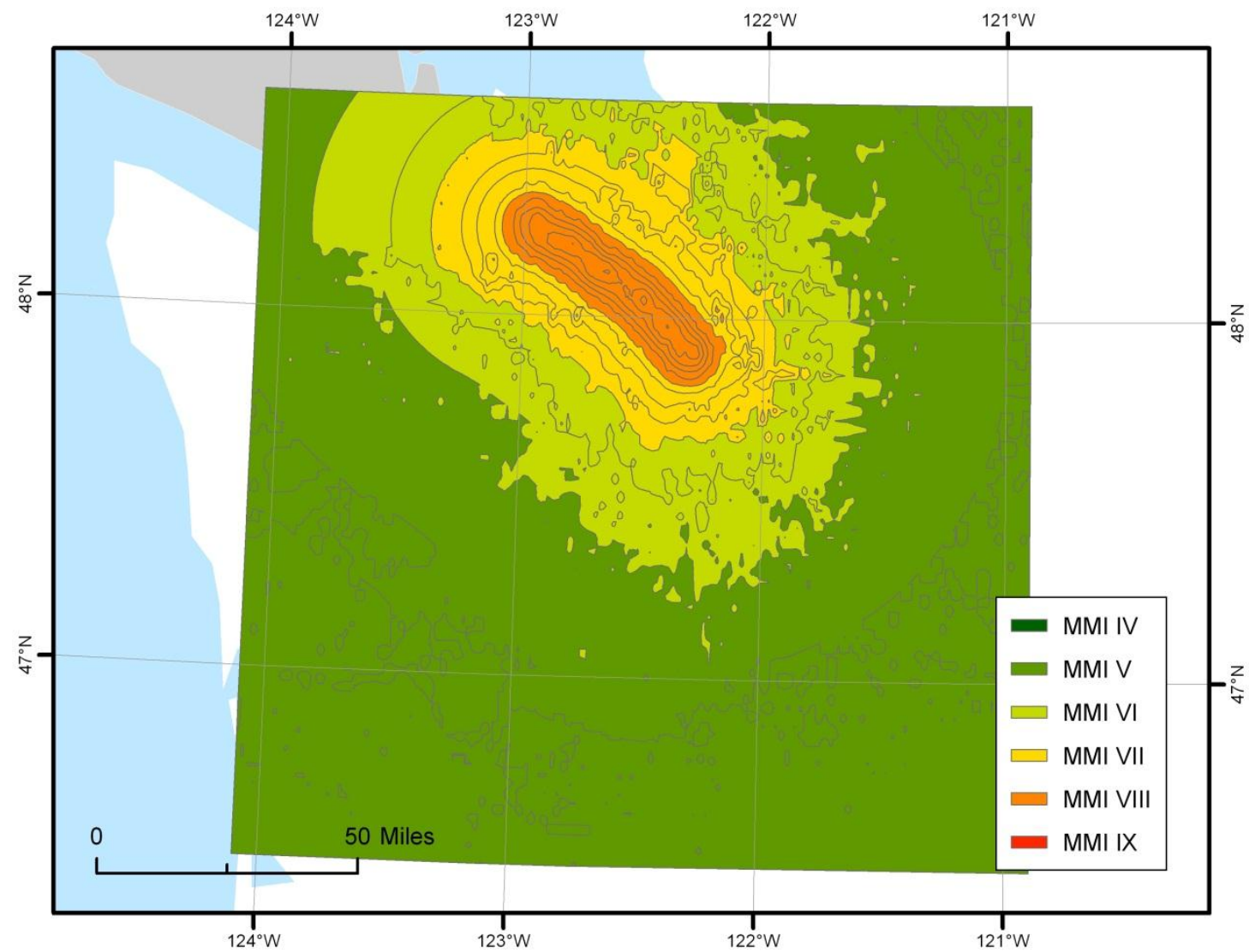

Figure 3. Earthquake scenario edge. The ShakeMap project defines the latitude and longitude extents for each earthquake scenario. These extents appear as explicit boundaries and do not cover the entire area the earthquake could actually impact.

Another constraint in Wood \& Ratliff's exposure assessment was that MMI classes were approximated from PGA data to be consistent with HAZUS-MH analyses. These approximations did not directly spatially match ShakeMap's MMI data. Finally, since the earthquake shaking data were scenarios and not the product of recorded data from actual earthquakes, the data obtained for each MMI class were estimates and did not definitively represent the potential exposure an actual earthquake could generate. Even 
historical earthquake data only have interpolated MMI shaking from explicit instrumental records for regions without instrumental data.

Table 1. Processed Washington State ShakeMap earthquakes

\begin{tabular}{|c|c|c|c|}
\hline $\begin{array}{l}\text { Earthquake } \\
\text { Name }\end{array}$ & ShakeMap Name & $\begin{array}{l}\text { Year } \\
\text { Generated }\end{array}$ & Notes \\
\hline Canyon River & $\begin{array}{l}\text { Canyon River Price Lake } \\
\text { M7.4 Scenario }\end{array}$ & 2009 & \\
\hline Cascadia & Cascadia M9.0 Scenario & 2011 & $\begin{array}{l}\text { Updated version of } \\
\text { USGS data }\end{array}$ \\
\hline Cascadia North & $\begin{array}{l}\text { Cascadia North M8.3 } \\
\text { Scenario }\end{array}$ & 2009 & \\
\hline Lake Creek & $\begin{array}{l}\text { Lake Creek M6.8 } \\
\text { Scenario }\end{array}$ & 2009 & \\
\hline Nisqually & $\begin{array}{l}17.0 \mathrm{~km} \text { NE of Olympia, } \\
\text { WA }\end{array}$ & 2001 & $\begin{array}{l}\text { Historical earthquake; } \\
\text { M6.8 }\end{array}$ \\
\hline Nisqually & Nisqually M7.2 Scenario & 2009 & \\
\hline Olympia & $\begin{array}{l}\text { Olympia Fault } \\
\text { (Aftershock) M5.7 } \\
\text { Scenario }\end{array}$ & 2011 & $\begin{array}{l}\text { Replaced SWIF } \\
\text { Southeast in USGS } \\
\text { work }\end{array}$ \\
\hline SeaTac & Seatac M7.2 Scenario & 2009 & \\
\hline Seattle & Seattle M7.2 Scenario & 2011 & $\begin{array}{l}\text { Revised version of } \\
\text { USGS data }\end{array}$ \\
\hline SWIF & $\begin{array}{l}\text { Southern Whidbey Island } \\
\text { Fault M7.4 Scenario }\end{array}$ & 2009 & \\
\hline SWIF Southeast & $\begin{array}{l}\text { Whidbey Island Fault } \\
\text { Scenario }\end{array}$ & 2000 & $\begin{array}{l}\text { M7.2; replaced with } \\
\text { Olympia in USGS work }\end{array}$ \\
\hline Tacoma & $\begin{array}{l}\text { Tacoma Fault M7.1 } \\
\text { Scenario }\end{array}$ & 2009 & \\
\hline
\end{tabular}

Since some of the earthquakes processed in the original USGS project did not dramatically impact many or all of the larger-scale spatial areas, only those scenarios affecting either King or Thurston Counties to at least a moderate extent (at least 50\%) were included. In addition, at least a small proportion (minimum 10\%) of the other 
county must also have been impacted. The total number of ShakeMap datasets for processing was reduced to twelve based on these criteria: eleven scenarios and one historical earthquake. The ShakeMap datasets being used are highlighted in Table 1, and the basic information and exposure for the twelve earthquakes selected for this analysis are presented in Appendix 2.

\section{Data and processing}

The earthquake scenario and historical PGA and MMI data were downloaded from the USGS ShakeMap project web site (USGS 2011b). Demographic data were acquired from the Census (U.S. Census Bureau, 2011e) for 2010 Census blocks (the smallest Census spatial unit), though Wood \& Ratliff analyzed 1990 Census and Census 2000 demographic data rather than 2010 Census data. The demographic variables processed included: (1) total population; and (2) total number of occupied housing units (U.S. Census Bureau, 2011g). Wood \& Ratliff's assessment further included total number of housing units as an exposure characteristic. All data were initially transformed to the Lambert Conformal Conic, North American Datum of 1983, High Accuracy Reference Network, State Plane, Washington, South, FIPS 4062 projection and datum for consistency between the various analyses.

Each earthquake was merged with the 2010 Census blocks using the Identity tool in ESRI's ArcGIS software suite to create a statewide file for each earthquake representing those blocks (or portions of blocks) potentially affected by the earthquake. The Identity tool breaks up one polygon GIS input dataset (in this case, Census blocks) based on the spatial location of polygons in a second polygon GIS input dataset (in this 
case, ShakeMap earthquake shaking). The initial block files had their demographics and area (needed later) in attribute fields associated with each individual block. The Census blocks were combined with Washington's county and community boundaries (U.S. Census Bureau, 2011e) using the Identity tool into a single GIS dataset prior to merging the earthquakes and blocks to determine exposure. Attributing the counties and communities each Census block falls in made summarizing each study area's results easier in Microsoft Excel later in the analysis since the county and community names were available to aggregate the block-level data on. After the counties, communities, and earthquake shaking were merged with the blocks, the area of each new area was calculated and used to estimate the final demographics. The final demographics were calculated by taking the ratio of each final area to the parent area and multiplying by the parent area's demographic data to provide the final area's demographic information.

The demographic data was exported for use in Microsoft Excel after being recalculated to reflect earthquake shaking, county, and community boundaries. A series of pivot tables were created to aggregate the demographic data to the community and the county level for each earthquake. The original PGA values were grouped in Excel using the ranges detailed in Appendix 1-this permitted the data to be broken down by MMI class as well as by community and county.

\section{Deviations from the parent assessment}

An initial replication of the GIS analysis used to produce Wood \& Ratliff’s 2011 results revealed an inconsistency in how ShakeMap data conform to the Washington state plane coordinate system. To accommodate for the spatial behavior of the shaking data 
shapefiles in the GIS software, the data were combined in ShakeMap's native global latitude/longitude geographic coordinate system rather than Washington's local projected coordinate system. Vector-based digital data like ShakeMap shapefiles only respond marginally well when transformed from a geographic coordinate system to a projected coordinate system; the detail of the PGA data was less than the MMI data, providing fewer vertices (the references that actually move to match the coordinate system) in different locations along the study area edges for the GIS application to use for coordinate system conformance.

The effects of the projection on the results were most obvious along the earthquake area's southern and northern boundaries. Fewer vertices existed on the earthquake boundaries to shift according to the projected coordinate system (though the projection difference actually affected all lines); outside of the MMI classes intersecting the edges of the earthquake data, the difference between the projected and geographic coordinate system analyses was minimal. The differences in population exposure due to projection distortion were no greater than 116 people at the state level, 71 people at the county level, and 37 people at the community level; MMI classes IV and V were disregarded since these two classes intersect the edges of the ShakeMap outputs and are not completely represented by the model results. Table 2 shows an example of how the projection impacted the PGA and MMI data for the Lake Creek earthquake. This particular earthquake returned the greatest difference between total affected population in MMI-grouped PGA and MMI. 
Table 2. Lake Creek MMI-grouped PGA total population exposure comparison

\begin{tabular}{|c|c|c|c|c|c|c|}
\hline & IV & $\mathbf{V}$ & VI & VII & VIII & IX \\
\hline $\begin{array}{l}\text { Projected } \\
\text { Coordinate } \\
\text { System }\end{array}$ & 126 & $4,150,287$ & 18,452 & 22,749 & 35,003 & 1,866 \\
\hline $\begin{array}{l}\text { Geographic } \\
\text { Coordinate } \\
\text { System }\end{array}$ & 126 & $4,160,621$ & 18,453 & 22,748 & 35,004 & 1,866 \\
\hline $\begin{array}{l}\text { Difference } \\
\text { (Geographic- } \\
\text { Projected) }\end{array}$ & 0 & $10,334^{\mathrm{a}}$ & 1 & -1 & 1 & 0 \\
\hline $\begin{array}{l}\text { Percent } \\
\text { Difference }\end{array}$ & $0.000 \%$ & $0.249 \%$ & $0.005 \%$ & $0.004 \%$ & $0.003 \%$ & $0.000 \%$ \\
\hline
\end{tabular}

\section{Final analysis}

For purposes of this analysis, 2010 Census data were used to examine exposure rather than Census 2000 or 1990 Census data. The GIS process detailed above was performed twice in its entirety, once with PGA polygon data and again with MMI polygon data. The only major difference between the PGA analysis and the MMI analysis was the grouping of the MMI values in Excel: rather than grouping by the values in Appendix 1, each spatial unit's MMI value was used as reported (no reclassification was required).

The PGA and MMI data were systematically sampled to see what MMI class existed at each location in addition to completing the exposure assessment to better see how extensive the differences between MMI-grouped PGA classes and official MMI classes were. The difference between the two MMI classifications was calculated and 
used to show how the two classifications were distributed. For an approximation of the overall impact across the study area(s) for all earthquakes, a compilation of difference was also established by showing for each sample point how many earthquakes had different MMI-grouped PGA classes and official MMI classes. The result, referred to as an inconsistency index, ranged from 0 to a possible maximum of 12 . Finally, the systematic sample data were used to compile an inconsistency/count ratio index ranging from 0 to 1 which showed the proportion of earthquakes with MMI class differences to the actual number of earthquakes affecting each point. For example, if a sample point was impacted by five out of seven total earthquakes, the ratio result of 0.7143 (5 divided by 7) was assigned to the point. A value of 1 shows that every earthquake represented at the sample point had a different official MMI class compared to its MMI-grouped PGA class.

Table 3. Spatial scale and sample sizes

\begin{tabular}{|c|c|c|}
\hline Study Area & Resolution $^{\mathbf{a}}$ & Number of Samples \\
\hline Washington & 0.10 & 1,894 \\
\hline King County & 0.05 & 264 \\
\hline Thurston County & 0.05 & 92 \\
\hline Seattle city & 0.01 & 438 \\
\hline Olympia city & 0.01 & 63 \\
\hline
\end{tabular}

${ }^{a}$ The units for the Resolution column are decimal degrees and represent the distance between points in the sample.

The number of sample points used for the spatial sampling portion of the assessment varied depending on the scale of the area being studied. For the state level, one set of sample data was generated. County data was extracted using a finer set of sample points to better show impact. Finally, community-level assessment was 
completed with an even finer-resolution sample so at least 30 sample points in each community were available (a minimum of 30 samples permits using parametric statistics to assess the results). Each sample was a systematic grid of points generated using ArcGIS's Create Fishnet tool with points not falling in the study area removed from the datasets. Table 3 shows the spatial scales and sample sizes/resolutions used.

The next section details the results from the exposure assessment and spatial sampling processes discussed above. Along with examples from the original data, some statistics and correlations are performed to further demonstrate or disprove the ability of one MMI dataset to approximate the other. Each of the three scales (state, county, and community) is detailed separately for each type of analysis. 


\section{Results}

The results from the exposure and sampling analyses revealed discrepancies between official MMI and MMI-grouped PGA classes. Official MMI class data spanned a wider range of classes than MMI-grouped PGA classes spatially. In the case of the Cascadia North Earthquake, the lowest official MMI shaking class reported in the MMI ShakeMap data was MMI I (the zones with an MMI value of I or II were not within any

of the study areas, however). The lowest MMI-grouped PGA class found in the Cascadia North PGA ShakeMap data was three classes higher than the MMI ShakeMap data at MMI IV. MMI III occurred in seven of the processed datasets for official MMI; this contrasted with MMI-grouped PGA, which never reported any exposure lower than MMI IV. Two scenario earthquakes (Cascadia and SWIF Southeast) reported MMI IX shaking using the official MMI data but not using the MMI-grouped PGA data.

The state level was the smallest-scale analysis of the three scales tested. The county level was less extensive than the state level spatially, showing a narrower range of exposure to MMI shaking (usually three MMI classes). The community level exposure had an even smaller range than the county level, never reporting more than three MMI shaking levels impacting a community.

A total of twelve earthquakes were processed (eleven scenarios, one historical). An important note to make before detailing any results from the comparison is that not every analyzed earthquake affected every spatial unit being examined. Any resulting statistics have taken into consideration the small sample size when appropriate. To more completely understand how MMI-grouped PGA classes differed from official MMI 
classes, the data were examined through both an exposure assessment and a spatial sampling of the two versions of MMI at each scale.

The exposure results from each type of MMI class (MMI-grouped PGA and official MMI) were plotted against each other to establish if any correlations existed in order to better understand how PGA ShakeMap data grouped into MMI classes compared to official MMI ShakeMap data. The goal of this correlation was to determine whether MMI-grouped PGA data serve as an accurate proxy of official MMI data or not. The correlation was completed for each of the three spatial scales (state, county, and community) as well as for each of the relevant MMI classes (in this case, individual and combined MMI V through IX). Scatterplots with trend lines and correlations can be found in Appendix 3 for MMI classes V through IX for each spatial scale.

\section{State-level demographic analysis}

At the state level, comparing MMI-grouped PGA and official MMI population exposure results revealed only a moderate correlation between MMI-grouped PGA and MMI. Very similar relationships appeared between total population and total occupied housing units; since the two demographic variables had such similar relationships, only population is discussed in future comparisons. Tables 4,5 , and 6 below show correlation coefficients for both population and occupied housing units for MMI classes V through IX as well as a combination of all five MMI classes. The minimal difference between the two demographics shown in Table 6 was the determining factor in only considering population for the rest of the analysis. 
Table 4. Correlation coefficients for MMI-grouped PGA and MMI for exposed population

\begin{tabular}{lcccccc}
\hline Spatial Area & V-IX & V & VI & VII & VIII & IX \\
\hline $\begin{array}{l}\text { State } \\
\text { County }\end{array}$ & 0.5429 & 0.3349 & 0.1614 & 0.5105 & 0.9862 & 0.2509 \\
$\quad$ & & & & & \\
$\quad$ King & 0.5144 & 0.4837 & 0.2786 & 0.4027 & 0.9926 & 0.0214 \\
$\quad \begin{array}{l}\text { Thurston } \\
\text { Community }\end{array}$ & 0.5551 & 0.3031 & 0.4123 & 0.6868 & 0.0081 & N/A \\
$\quad$ Seattle & 0.4816 & 0.5674 & 0.3312 & 0.4737 & 1 & N/A \\
$\quad$ Olympia & 0.6144 & 0.1585 & 0.5294 & 0.5193 & N/A & N/A \\
\hline
\end{tabular}

Table 5. Correlation coefficients for MMI-grouped PGA and MMI for exposed occupied housing units

\begin{tabular}{lcccccc}
\hline Spatial Area & V-IX & V & VI & VII & VIII & IX \\
\hline $\begin{array}{l}\text { State } \\
\text { County }\end{array}$ & 0.5426 & 0.3453 & 0.1552 & 0.5335 & 0.9892 & 0.2316 \\
$\quad$ & & & & & \\
$\quad$ King & 0.5106 & 0.4922 & 0.2801 & 0.4205 & 0.9942 & 0.0186 \\
$\quad \begin{array}{l}\text { Thurston } \\
\text { Community }\end{array}$ & 0.5636 & 0.2993 & 0.4204 & 0.6957 & 0.0081 & N/A \\
$\quad$ Seattle & 0.4843 & 0.5686 & 0.3137 & 0.4627 & 1 & N/A \\
$\quad$ Olympia & 0.6312 & 0.1693 & 0.5370 & 0.5205 & N/A & N/A \\
\hline
\end{tabular}

Table 6. Difference between correlation coefficients for MMI-grouped PGA and MMI for exposed population and exposed occupied housing units

\begin{tabular}{lcccccc}
\hline Spatial Area & V-IX & V & VI & VII & VIII & IX \\
\hline State & 0.0003 & -0.0104 & 0.0062 & -0.0230 & -0.0030 & 0.0193 \\
County & & & & & & \\
$\quad$ King & 0.0038 & -0.0085 & -0.0015 & -0.0178 & -0.0016 & 0.0028 \\
$\quad$ Thurston & -0.0085 & 0.0038 & -0.0081 & -0.0089 & 0 & N/A \\
Community & & & & & & \\
$\quad$ Seattle & -0.0027 & -0.0012 & 0.0175 & 0.0110 & 0 & N/A \\
$\quad$ Olympia & -0.0168 & -0.0108 & -0.0076 & -0.0012 & N/A & N/A \\
\hline
\end{tabular}


A slightly different picture emerged when the exposure observations were assessed for specific MMI classes at the state level than for the aggregated MMI classes. The correlation between MMI and PGA was weakest in the MMI VI class for the state (0.1614). Correlations between MMI and PGA were stronger in both directions away from MMI VI, though the correlations were still moderately strong at best (MMI V: 0.3349; MMI VII: 0.5105). The exposure recorded in the MMI IX class was an exception to the pattern: MMI IX exposure was minimal since such intense shaking rarely occurred and was sparse when actually present.

Official MMI classes generally estimated higher population exposures in the lower MMI classes when differences between MMI-grouped PGA class and official MMI class exposures were calculated. In contrast, MMI-grouped PGA classes estimated higher exposures more frequently in the middle MMI classes. The highest MMI classes generally split equally between higher exposures using MMI-grouped PGA classes and higher exposures using official MMI classes (the MMI XI class had slightly more occurrences of official MMI reporting higher exposure). The two SWIF earthquakes demonstrated this trend clearly: official MMI exposure was higher in the two lowest MMI classes, MMI-grouped PGA exposure was higher for the middle MMI classes, and official MMI exposure was again higher for the two highest MMI classes. The state population exposures and differences for the SWIF and SWIF Southeast earthquakes can be found in Table 7 .

The inconsistencies shown in the high MMI class exposures possibly related to the overall MMI class range for each dataset: not every earthquake had data for every 
MMI class. The formulae used to calculate MMI from PGA and PGV would also have affected the results. High MMI classes use PGV instead of PGA, so variations in the high MMI classes would reflect PGV rather than PGA.

Table 7. State population exposures for SWIF and SWIF Southeast earthquakes

\begin{tabular}{cccccccc}
\hline Category & III & IV & V & VI & VII & VIII & IX \\
\hline SWIF & & & & & & & \\
PGA & 0 & 0 & $1,462,901$ & $1,356,826$ & $1,207,863$ & 467,810 & 165,431 \\
MMI & 29 & 408,039 & $1,199,482$ & $1,312,110$ & $1,025,017$ & 474,636 & 241,518 \\
Diff. $^{a}$ & -29 & $-408,039$ & 263,419 & 44,716 & 182,847 & $-6,826$ & $-76,087$ \\
SWIF SE & & & & & & & \\
PGA & 0 & 0 & $1,362,166$ & $1,785,260$ & $1,014,426$ & 288,664 & 0 \\
MMI & 0 & 134,757 & $1,473,228$ & $1,646,836$ & 835,818 & 314,469 & 45,409 \\
Diff. $^{\text {a }}$ & 0 & $-134,757$ & $-111,061$ & 138,425 & 178,608 & $-25,805$ & $-45,409$ \\
\hline
\end{tabular}

${ }^{a}$ Diff. shows the difference between MMI-grouped PGA and official MMI exposures (PGA-MMI).

\section{County-level demographic analysis}

At the county level, difference patterns similar to the state level were visible between MMI-grouped PGA and official MMI exposure. The exposure correlation between MMI-grouped PGA and official MMI was moderate when MMI classes V-IX were aggregated. Unlike the state-level correlations, the weakest correlations were the highest MMI class occurrences: MMI class IX for King County and MMI class VIII for Thurston County (Thurston County had no data to correlate for MMI class IX). MMI class VI was still relatively weak compared to adjacent MMI classes, but the correlations were higher for both counties compared to the state.

Official MMI classes had higher exposures than MMI-grouped PGA classes in the low and high MMI classes; mid-level MMI class exposures were generally higher for 
MMI-grouped PGA classes than official MMI classes. This trend was somewhat harder to see at the county level since a smaller range of MMI classes affected the counties.

King County, due to its larger spatial extent compared to Thurston County, saw more of the exposure difference pattern present at the state level. Tables 8 and 9 show King and Thurston County exposures for the SWIF and SWIF Southeast earthquakes; the differences between the MMI and MMI-grouped PGA exposures are also included.

Table 8. King County population exposures for SWIF and SWIF Southeast earthquakes

\begin{tabular}{cccccccc}
\hline Category & III & IV & V & VI & VII & VIII & IX \\
\hline SWIF & & & & & & & \\
PGA & 0 & 0 & 50,725 & 891,190 & 868,923 & 113,800 & 6,611 \\
MMI & 0 & 1 & 125,998 & 904,529 & 720,915 & 162,151 & 17,655 \\
Diff. & 0 & -1 & $-56,623$ & $-13,339$ & 148,007 & $-48,351$ & $-11,044$ \\
SWIF SE & & & & & & & \\
PGA & 0 & 0 & 131,798 & $1,362,768$ & 436,682 & 0 & 0 \\
MMI & 0 & 5 & 340,985 & $1,258,226$ & 332,033 & 0 & 0 \\
Diff. & 0 & -5 & $-209,187$ & 104,542 & 104,649 & 0 & 0 \\
\hline
\end{tabular}

Table 9. Thurston County population exposures for SWIF and SWIF Southeast earthquakes

\begin{tabular}{cccccccc}
\hline Category & III & IV & V & VI & VII & VIII & IX \\
\hline SWIF & & & & & & & \\
PGA & 0 & 0 & 252,264 & 0 & 0 & 0 & 0 \\
MMI & 0 & 207,761 & 44,503 & 0 & 0 & 0 & 0 \\
Diff. & 0 & $-207,761$ & 207,761 & 0 & 0 & 0 & 0 \\
SWIF SE & & & & & & & \\
PGA & 0 & 0 & 251,614 & 650 & 0 & 0 & 0 \\
MMI & 0 & 34,052 & 218,208 & 4 & 0 & 0 & 0 \\
Diff. & 0 & $-34,052$ & 33,406 & 646 & 0 & 0 & 0 \\
\hline
\end{tabular}




\section{Community-level demographic analysis}

Like the state and county levels, community-level exposure correlations were still generally moderate at best and weak at worst. The overall correlation between MMIgrouped PGA and official MMI for MMI classes V-IX was strongest for Olympia, with a correlation of 0.6144 compared to Seattle's correlation of 0.4816 . Seattle actually had one MMI class correlation that was perfect: the perfect relationship was a result of only two earthquakes affecting Seattle at that particular MMI class. The weakest correlations were MMI class VI for Seattle and MMI class V for Olympia (0.3312 and 0.1585, respectively), with the exception of MMI class XI for both communities and MMI class VIII for Olympia due to lack of any exposure for either community at those levels.

The exposure populations for each community still vaguely reflected the trend of official MMI exposing larger populations in the low and high classes while MMIgrouped PGA exposed larger populations in the middle classes. The larger spatial scale severely limited the ability of the data to fully represent the trends visible at the smaller county and state scales. Tables 10 and 11 show Seattle and Olympia population exposures for the SWIF and SWIF Southeast earthquakes; the differences between the two MMI class types are also provided. The official MMI exposures were greater in the low MMI classes for both earthquakes, but with only two classes exposed for Olympia, the data did not show the reassertion of greater official MMI exposure in the high classes (Seattle did, however, have this trend in the SWIF results). This suggests that as scale gets larger the impact of the differences between official MMI data and MMI-grouped PGA data becomes more difficult to predict. 
Table 10. Seattle city population exposures for SWIF and SWIF Southeast earthquakes

\begin{tabular}{cccccccc}
\hline Category & III & IV & V & VI & VII & VIII & IX \\
\hline SWIF & & & & & & & \\
PGA & 0 & 0 & 0 & 215,189 & 393,471 & 0 & 0 \\
MMI & 0 & 0 & 0 & 298,175 & 310,473 & 12 & 0 \\
Diff. & 0 & 0 & 0 & $-82,987$ & 82,999 & -12 & 0 \\
SWIF SE & & & & & & & \\
PGA & 0 & 0 & 0 & 413,971 & 194,689 & 0 & 0 \\
MMI & 0 & 0 & 4,479 & 482,508 & 121,673 & 0 & 0 \\
Diff. & 0 & 0 & $-4,479$ & $-68,538$ & 73,016 & 0 & 0 \\
\hline
\end{tabular}

Table 11. Olympia city population exposures for SWIF and SWIF Southeast earthquakes

\begin{tabular}{cccccccc}
\hline Category & III & IV & V & VI & VII & VIII & IX \\
\hline SWIF & & & & & & & \\
PGA & 0 & 0 & 46,478 & 0 & 0 & 0 & 0 \\
MMI & 0 & 34,391 & 12,087 & 0 & 0 & 0 & 0 \\
Diff. & 0 & $-34,391$ & 34,391 & 0 & 0 & 0 & 0 \\
SWIF SE & & & & & & & \\
PGA & 0 & 0 & 46,478 & 0 & 0 & 0 & 0 \\
MMI & 0 & 3,724 & 42,754 & 0 & 0 & 0 & 0 \\
Diff. & 0 & $-3,724$ & 3,724 & 0 & 0 & 0 & 0 \\
\hline
\end{tabular}

\section{State-level sample exposure}

At the state level, spatial differences in exposure between official MMI and MMIgrouped PGA classes were prevalent. Bands of MMI class consistency and inconsistency dominated for the most part, with patches of inconsistency also manifesting sporadically. Unlike the demographic exposure results, the spatial sample was both numerous enough and normally-distributed enough to perform more informative parametric statistics (the frequency distributions for the spatial samples can be found in Appendix 4). A basic 
pattern of inconsistency did emerge across space-MMI-grouped PGA classes tended to be classified higher than official MMI classes in the lower levels, and official MMI classes tended to be classified higher than MMI-grouped PGA classes in the higher levels. Figure 4 illustrates this phenomenon: Figure 4a shows the lower level discrepancy and Figure $4 \mathrm{~b}$ shows the higher level discrepancy.

a)

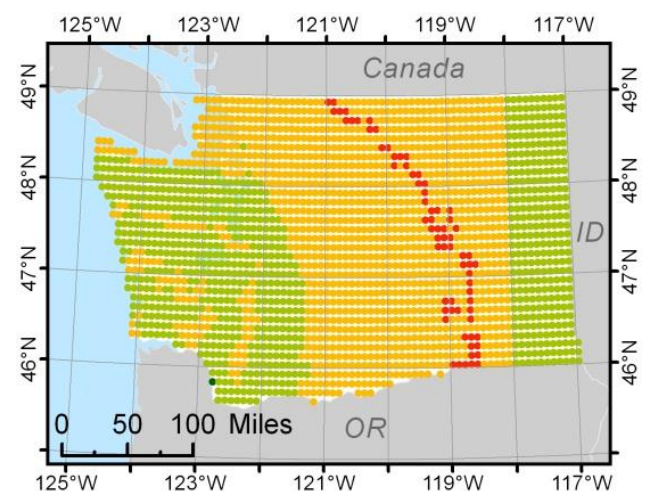

b)

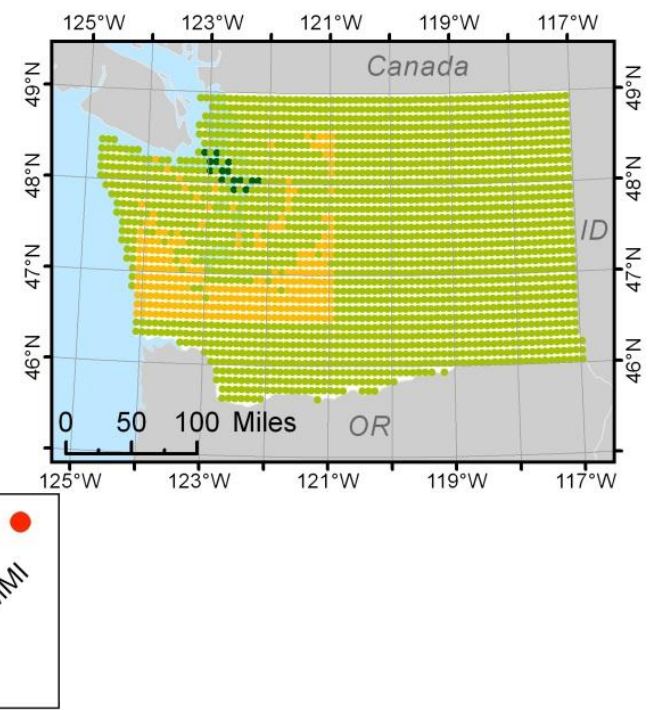

Figure 4. State-level scenario MMI class differences: a) Cascadia North; b) SWIF Southeast. Points east of $118^{\circ} \mathrm{W}$ longitude did not fall in any of the earthquake extents.

A paired-samples t-test revealed significant differences at the state scale between MMI-grouped PGA values and official MMI values for all twelve earthquakes. This suggests that a significant amount of variation occurred between the means of the two MMI datasets. Table 12 shows the results of the paired-samples t-tests for each earthquake at the state level (descriptive statistics for each spatial level can be found in Appendix 5). The extremely high t-scores reported for each earthquake implies that many sample points did not have the same values in both the MMI-grouped PGA dataset and the official MMI dataset. 
Table 12. State-level paired-sample t-test statistics

\begin{tabular}{lcc}
\hline Earthquake & t-score $^{\mathbf{a}}$ & Sig $^{\mathbf{b}}$ \\
\hline Canyon River & 13.973 & 0.000 \\
Cascadia & 47.112 & 0.000 \\
Cascadia North & 63.938 & 0.000 \\
Lake Creek & 18.501 & 0.000 \\
Nisqually (h) & 14.276 & 0.000 \\
Nisqually & 16.296 & 0.000 \\
Olympia & 10.218 & 0.000 \\
SeaTac & 16.692 & 0.000 \\
Seattle & 17.394 & 0.000 \\
SWIF & 23.556 & 0.000 \\
SWIF Southeast & 15.298 & 0.000 \\
Tacoma & 19.655 & 0.000 \\
\hline
\end{tabular}

${ }^{a} \mathrm{t}$-score is the two-tailed result from a paired-samples t-test where the MMI-grouped PGA value for a sample is the first input and the official MMI value for the sample is the second input.

${ }^{\mathrm{b}}$ Sig is the significance at $\mathrm{p}=0.05, \mathrm{t}_{\text {crit }}=1.960, \mathrm{df}=1,893$

One possible source of distortion in the statistics (which only significantly applied at the state level) was the variation in spatial extent between earthquakes. However, any point that fell outside of an earthquake region was assigned a value of zero in both MMIgrouped PGA and official MMI data. Since the number of zeros generated from the various earthquakes would have paired across MMI datasets, the number of zero pairs should not have had an impact on the calculated statistics. If anything, the frequency of paired zeros would have decreased the likelihood of the statistics returning significant results. 


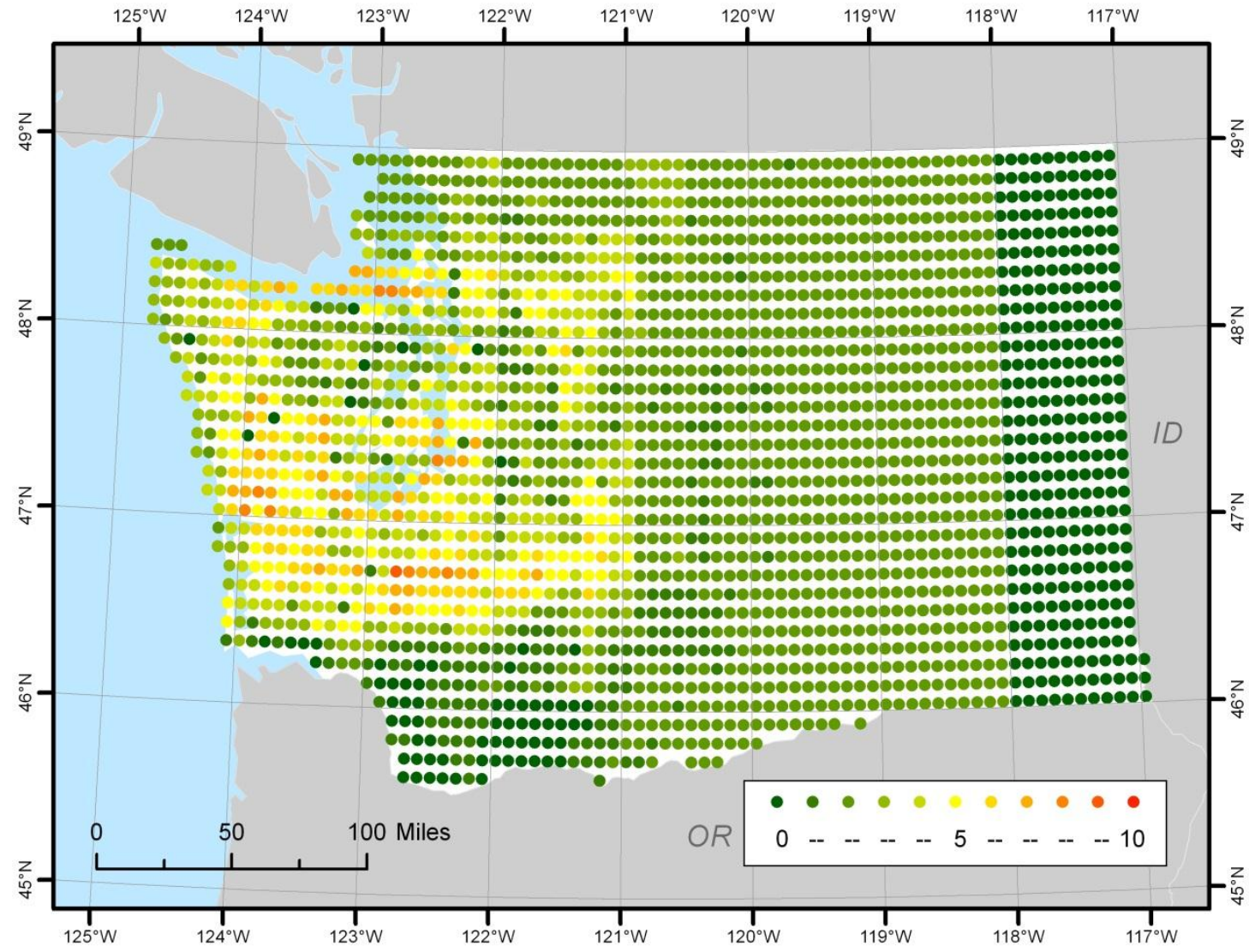

Figure 5. State-level spatial inconsistency index. Inconsistency ranges from dark green (no inconsistencies) up to red (ten inconsistencies). None of the twelve processed earthquakes affected the dark green band running east from $118^{\circ} \mathrm{W}$ longitude.

An inconsistency index showing for each point the number of discrepancies between official MMI and MMI-grouped PGA further suggested that the two MMI datasets were not comparable. Out of a possible twelve earthquakes, nearly $13 \%$ of the sample points (244 out of 1,894$)$ had inconsistency for at least five earthquakes. The mode inconsistency index value for the state was two: the unusually low value was a result of the more extensive Cascadia and Cascadia North earthquakes. The samples identified a small area just south of Seattle where the MMI-grouped PGA classes and 
official MMI classes were inconsistent with each other in nine of the twelve earthquakes.

Figure 5 shows the results of the aggregated inconsistency index.

The inconsistency index alone does not tell the full story regarding the exposure to earthquakes spatially. The number of inconsistent earthquakes is only informative if placed in context to the total number of earthquakes impacting each sample point. A new ratio index dividing the number of inconsistent earthquakes for each sample point by the total number of earthquakes for each sample point was compiled for this reason.

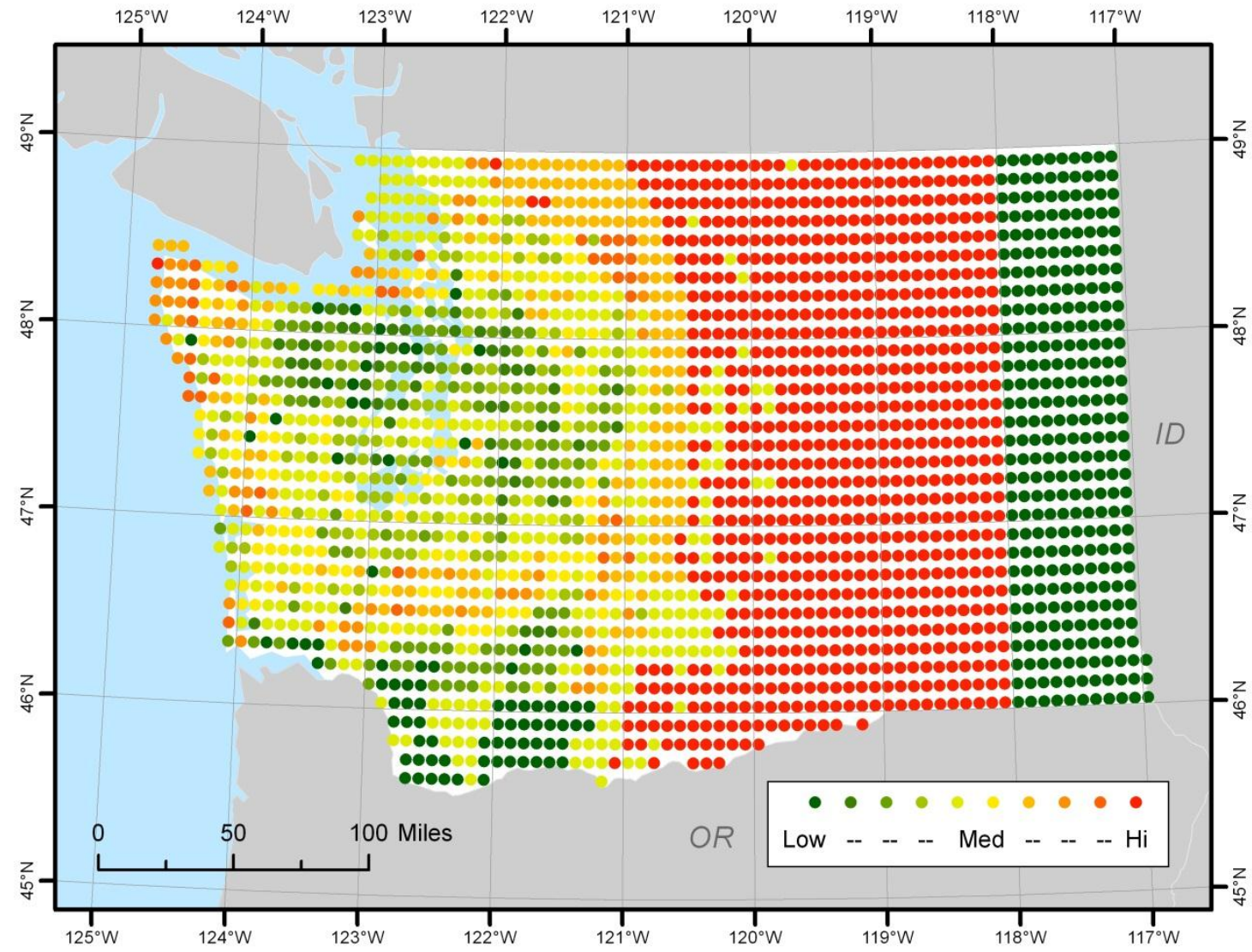

Figure 6. State-level inconsistency/count ratio index. Ratio ranges from dark green (inconsistencies infrequent compared to earthquakes) to red (inconsistencies frequent compared to earthquakes). None of the twelve processed earthquakes affected the dark green band covering the area east of $118^{\circ} \mathrm{W}$ longitude. 
The inconsistency/ratio index provides an alternate view of the spatial impact of the difference between MMI-grouped PGA and official MMI. For display purposes, the ratios were aggregated to ten classes (each class representing ten percent) and nominally grouped from low to high inconsistency relative to the number of earthquakes for the point.

All twelve earthquakes spatially potentially affected the state level: the range was eleven (from a minimum of two to a maximum of twelve earthquakes). Variation from the original inconsistency index was fairly prevalent in the inconsistency/count ratio index because of the wide range. The result for the state level can be seen in Figure 6some striking differences can be seen between the two indices even while the basic pattern from the original inconsistency index is still visible. Portions of the Pacific coast were inconsistent in only a few earthquakes, but only a few earthquakes even affected this part of the state. Being able to identify where inconsistency occurs frequently relative to the number of events can help determine where more careful considerations need to be made before choosing one type of shaking data over another. In general, however, PGA-grouped MMI and official MMI were significantly different in this assessment and therefore not interchangeable.

\section{County-level sample exposure}

Spatial differences could still be seen between MMI-grouped PGA and official MMI data at the county level, but the differences were less varied than at the state level. While the state-level Cascadia North Earthquake had a band of sample points where the difference between the two MMI datasets was two, the county level did not. The county- 
level version of SWIF Southeast likewise did not show any points where official MMI was classified higher than MMI-grouped PGA while the state-level sample did (Figure 7b and Figure 7d). SWIF, unlike SWIF Southeast, did show some points where official MMI was higher than MMI-grouped PGA; this was only for King County (Figure 7a), not Thurston County (which best showed the variation in differences in Figure 7c by the Cascadia Earthquake).

County-level paired-samples t-test statistics for the twelve earthquakes also generally showed that the differences between the means were statistically significant. Table 13 shows the county-level t-statistics.

Table 13. County-level paired-sample t-test statistics

\begin{tabular}{lcccc} 
& \multicolumn{2}{c}{ King County } & \multicolumn{2}{c}{ Thurston County } \\
\cline { 2 - 5 } Earthquake & t-score & Sig $^{\mathbf{a}}$ & t-score & Sig $^{\mathbf{b}}$ \\
\hline Canyon River & 2.473 & 0.014 & 5.508 & 0.000 \\
Cascadia & 11.679 & 0.000 & 3.667 & 0.000 \\
Cascadia North & 11.960 & 0.000 & 4.542 & 0.000 \\
Lake Creek & 12.259 & 0.000 & 5.508 & 0.000 \\
Nisqually (h) & 6.235 & 0.000 & 1.000 & 0.320 \\
Nisqually & 11.581 & 0.000 & 16.523 & 0.000 \\
Olympia & 5.586 & 0.000 & 12.755 & 0.000 \\
SeaTac & 17.901 & 0.000 & 9.539 & 0.000 \\
Seattle & 8.465 & 0.000 & 4.867 & 0.000 \\
SWIF & 5.232 & 0.000 & 25.886 & 0.000 \\
SWIF Southeast & 6.752 & 0.000 & 9.334 & 0.000 \\
Tacoma & 8.795 & 0.000 & 4.705 & 0.000 \\
\hline Ting County is the significance at $\mathrm{p}=0.05, \mathrm{t}_{\text {crit }}=1.977, \mathrm{df}=263$ \\
a Sig for for Thurston County is the significance at $\mathrm{p}=0.05, \mathrm{t}_{\text {crit }}=1.990, \mathrm{df}=91$
\end{tabular}


Unlike the state level, one of the county-level earthquakes did show insignificant differences between MMI-grouped PGA and official MMI-Thurston County's historical Nisqually Earthquake had a significance value of 0.32 , far larger than the 0.05 significance level established for this analysis. King County's Canyon River Earthquake also had a somewhat large significance value: 0.014 was not large enough to say the differences between the two MMI variations was simply random but the significance value was much larger than the remaining significance values for King County. The ttests revealed that the differences between MMI-grouped PGA data and official MMI data still varied enough at the county level for the dataset being used to have an impact on exposure analyses. The type of earthquake may also have an impact since the one historical earthquake did have an insignificant result for one county while all of the scenario earthquakes were statistically significant.

The banding caused by the variations in class difference visible in the state-level spatial sampling assessment was less obvious at the county level but could still sometimes be seen when mapped. Figure 7 a has diagonal inconsistency banding running from the northeast to the southwest and Figure 7d shows two distinct patches of inconsistency/consistency. More sample points could potentially have caught the missing banding at the county level, but given the wide extent of the earthquakes, the spatial scale of the counties may simply have been too large to encompass the bands of inconsistency. Spatial inconsistency at the county level was still quite varied. King County had inconsistency ranging from no inconsistency up to ten inconsistent earthquakes. The fact that some samples had no inconsistent results was interesting since King County had its 
entire spatial extent affected by half of the analyzed earthquakes (this was by design since the earthquakes were selected based on how much of each county was impacted).

Thurston County also had a fairly extensive range of inconsistency, but the range was smaller than in King County.

a)

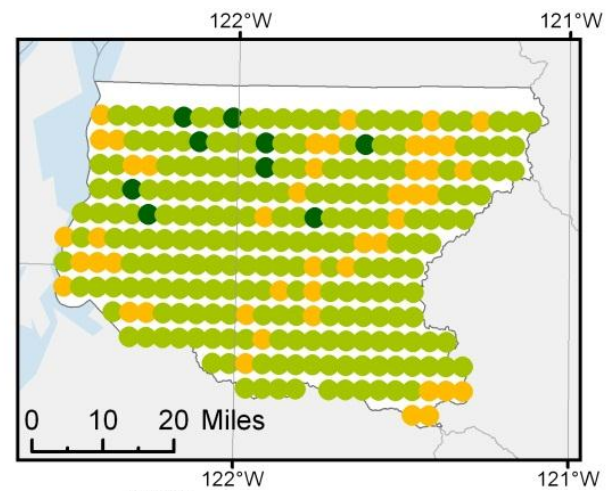

c)

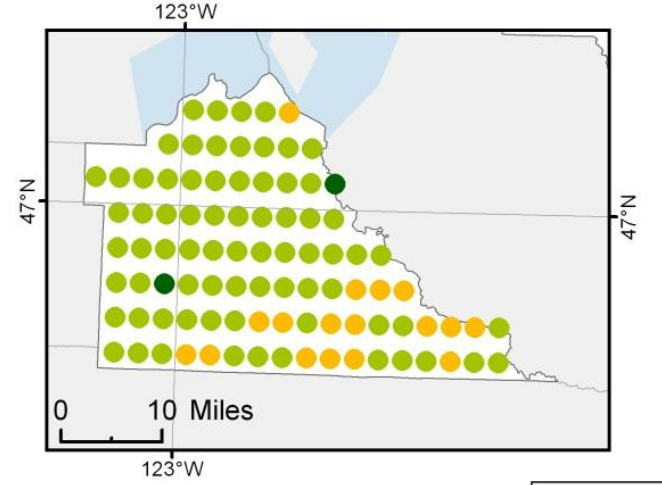

b)

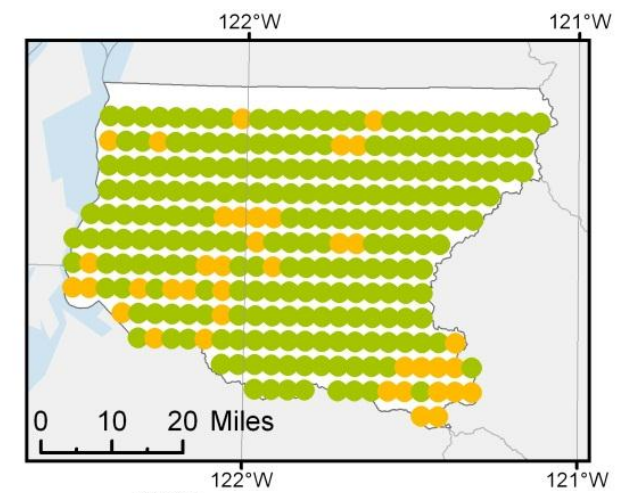

d)

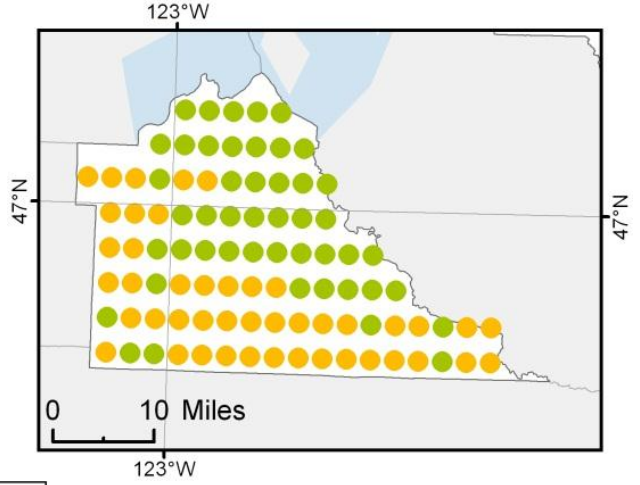

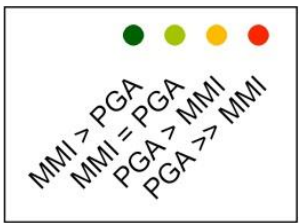

Figure 7. County-level scenario MMI class differences: a) King County SWIF; b) King County SWIF Southeast; c) Thurston County Cascadia; d) Thurston County SWIF Southeast.

All sample points in Thurston County had at least one inconsistent earthquake, with the maximum sample inconsistency being eight. The majority of sample points in King County had an inconsistency index of two, and Thurston County's mode inconsistency index was four. $20 \%$ of the sample points in King County had an inconsistency index of 
at least five; $46 \%$ of Thurston County's sample points had an inconsistency index value of five or greater.

a)

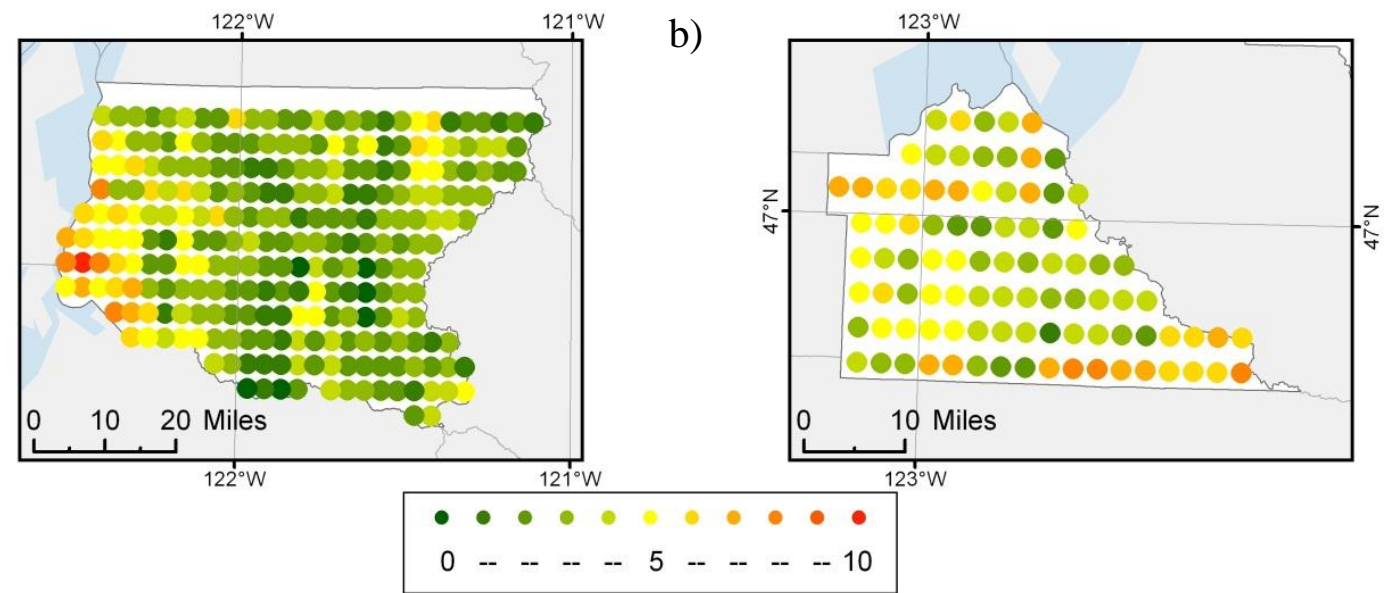

Figure 8. County-level spatial inconsistency index: a) King County; b) Thurston County. Inconsistency ranges from dark green (no inconsistencies) up to red (ten inconsistencies).

a)

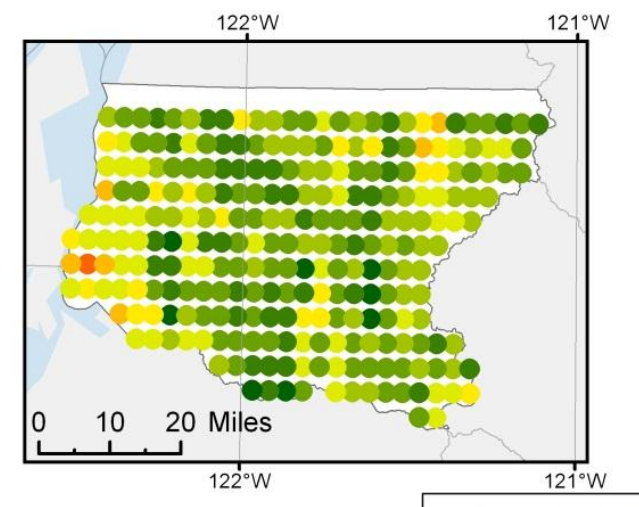

b)

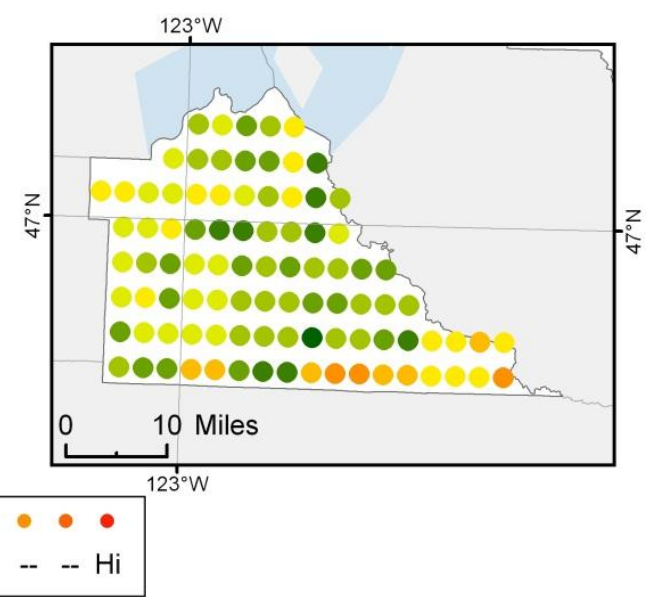

Figure 9. County-level inconsistency/count ratio index: a) King County; b) Thurston County. Ratio ranges from dark green (inconsistencies infrequent compared to earthquakes) to red (inconsistencies frequent compared to earthquakes).

Inconsistency seemed to be more pronounced at the county level than at the state level. The scale of the study region was the likely cause for this phenomenon since the larger-scale counties had fewer sample points but covered far less area, increasing the likelihood that a larger proportion of samples would be inconsistent. Figure 8 shows the spatial inconsistency samples for the two county-level analyses. Thurston County had a 
smaller number of sample points since the county's total area was less than King County but the sample resolution was the same for both counties.

The basic pattern from the inconsistency index was repeated in the inconsistency/count ratio index at the county level. The actual range of earthquakes for King County was seven (six to twelve), and the range for Thurston County was two (eleven to twelve). The overall variation in pattern between the two indices was barely visible in Thurston County due to the small spatial range in earthquakes, whereas King County's larger range allowed for more spatial variation. Figures $9 \mathrm{a}$ and $9 \mathrm{~b}$ show the inconsistency/count ratio index results for both King County and Thurston County. The

wide range in variation suggested that, like at the state level, MMI-grouped PGA data and official MMI data were too different to be used interchangeably.

\section{Community-level sample exposure}

The community level, like the county level, showed less spatial variation in inconsistency than the smaller-scale regions. However, inconsistencies could be seen even at the communities' large scale. Figures 10a and 10b are good examples of this: even though Seattle is only a small part of King County, differences in both directions between official MMI and MMI-grouped PGA were visible in the sample data for the SWIF and SWIF Southeast earthquakes.

Olympia, like Thurston County, is smaller than its King County counterpart. Olympia's smaller size translated to a smaller variety of inconsistencies for Olympia-all earthquakes showed either no difference between official MMI and MMI-grouped PGA classes or the MMI-grouped PGA class was one higher than the official MMI class. The 
results from the Seattle and SWIF Southeast earthquakes for Olympia are shown in Figures 10c and 10d. Seattle had only a few earthquakes where official MMI was one higher than MMI-grouped PGA. The remaining earthquakes affecting Seattle showed no difference between the two MMI types or that the MMI-grouped PGA class was higher than the official MMI class.

a)

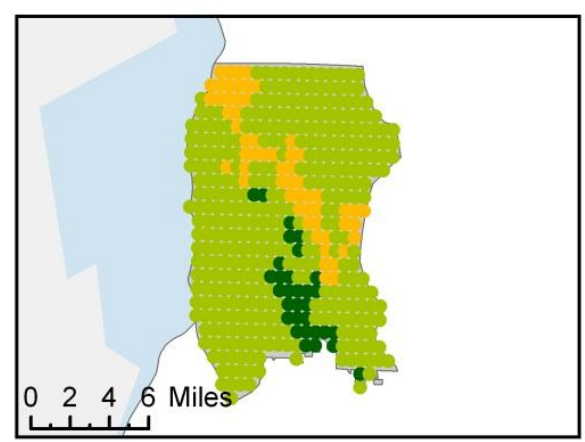

c)

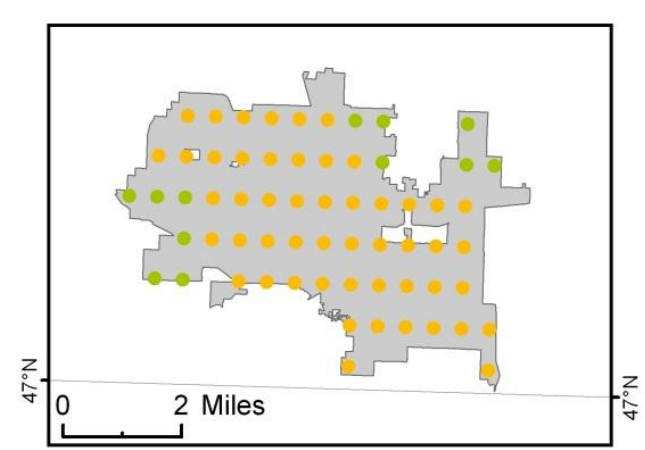

b)

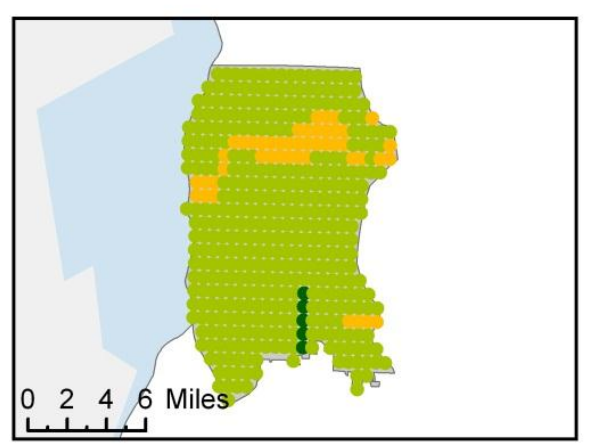

d)

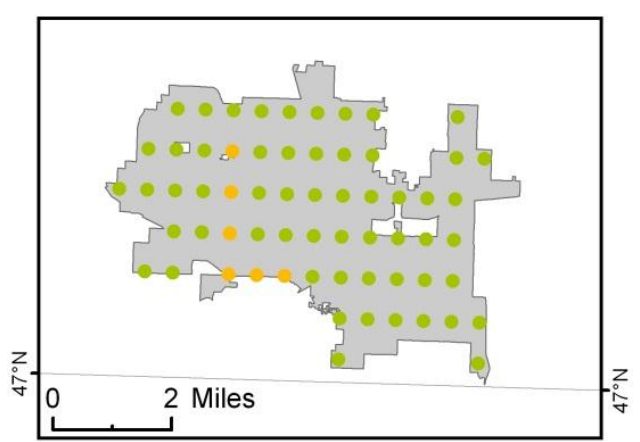

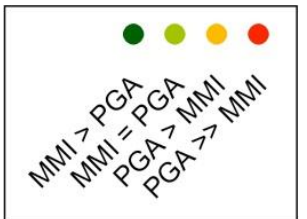

Figure 10. Community-level scenario MMI class differences: a) Seattle SWIF; b) Seattle SWIF Southeast; c) Olympia Seattle; d) Olympia SWIF Southeast.

Community-level paired-samples t-test results were, like the county and state levels, mostly statistically significant. Olympia more frequently returned significance values larger than any other study areas (Canyon River, SWIF Southeast, and Tacoma 
scenarios statistically significant; historical Nisqually statistically insignificant).

Decreasing significance values at the community level suggested that the community level was slightly less affected by the difference between MMI-grouped PGA and official MMI data than the smaller-scale study regions. The historical earthquake was once again statistically insignificant, suggesting that the type of earthquake may have an effect on the data. Coupled with the increased number of potentially insignificant earthquake results overall, scale seemed to have some effect on the impact the two versions of MMI had on exposure.

Table 14. Community-level paired-sample t-test statistics

\begin{tabular}{lcccc}
\cline { 2 - 5 } & \multicolumn{2}{c}{ Seattle city } & \multicolumn{2}{c}{ Olympia city } \\
\hline Earthquake & t-score & Sig $^{\mathbf{a}}$ & $\mathbf{t}$-score & Sig $^{\mathbf{b}}$ \\
\hline Canyon River & 4.573 & 0.014 & 2.050 & 0.045 \\
Cascadia & 27.050 & 0.000 & N/A & N/A \\
Cascadia North & N/A & N/A & N/A & N/A \\
Lake Creek & 88.798 & 0.000 & 43.486 & 0.000 \\
Nisqually (h) & 12.474 & 0.000 & 1.761 & 0.083 \\
Nisqually & 18.987 & 0.000 & 5.971 & 0.000 \\
Olympia & 15.010 & 0.000 & 11.546 & 0.000 \\
SeaTac & 31.487 & 0.000 & 9.393 & 0.000 \\
Seattle & 9.655 & 0.000 & 16.233 & 0.000 \\
SWIF & 2.886 & 0.004 & 15.442 & 0.000 \\
SWIF Southeast & 5.963 & 0.000 & 2.555 & 0.013 \\
Tacoma & 10.108 & 0.000 & 2.555 & 0.013 \\
\hline
\end{tabular}

${ }^{a}$ Sig for Seattle city is the significance at $p=0.05, t_{\text {crit }}=1.973, \mathrm{df}=437$

${ }^{\mathrm{b}} \mathrm{Sig}$ for Olympia city is the significance at $\mathrm{p}=0.05, \mathrm{t}_{\text {crit }}=1.999, \mathrm{df}=62$

At the community level, the potential for invalid t-test statistics was increasedwhen all sample pairs match and the difference between means is zero, no test statistic 
can be calculated. The Cascadia and Cascadia North earthquakes were extensive enough in area that the two MMI versions never differed from each other at the community scale. Most earthquakes were still different enough through the sampling to warrant careful consideration even at the community scale of which version of the MMI data are being used for analysis, however.

The large-scale community level did show some inconsistency banding, just like the previous two scales. However, the visible banding may simply have shown patches of inconsistency rather than actual bands - the large scale of the community-level analysis did not permit distinguishing between bands and patches. For example, Figure 10c shows a majority of sample points where MMI-grouped PGA was one class higher than MMI for Olympia in the Seattle Earthquake. Because Olympia covers a small spatial area, the diagonal band that appears to be running through the city may actually be a patch of difference rather than a band as was seen at the state level. The band of inconsistency running through Seattle's SWIF Southeast Earthquake results (shown in Figure 10b) seems more likely to be a band because of its narrowness compared to its extent.

The spatial inconsistency index showed nearly as much variation at the community level as it did at the county level. Seattle's inconsistency ranged from none up to eight inconsistent earthquakes affecting the community. Olympia also showed a wide range of inconsistency, though the range was the smallest of all analyzed areas-a minimum of two inconsistent earthquakes and a maximum of eight inconsistent 
earthquakes. The spatial inconsistency index results for Seattle and Olympia can be seen in Figures 11a and 11b.

a)

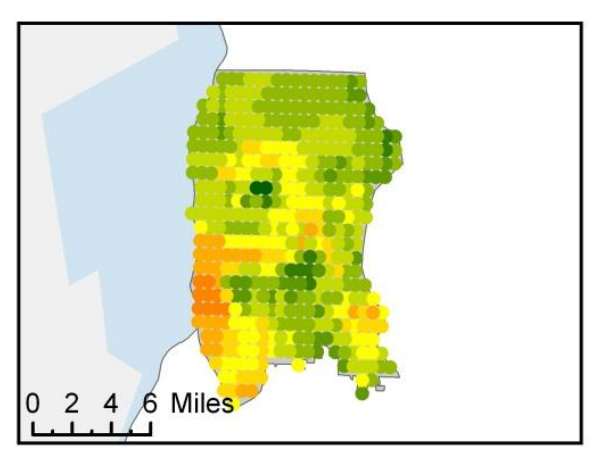

b)

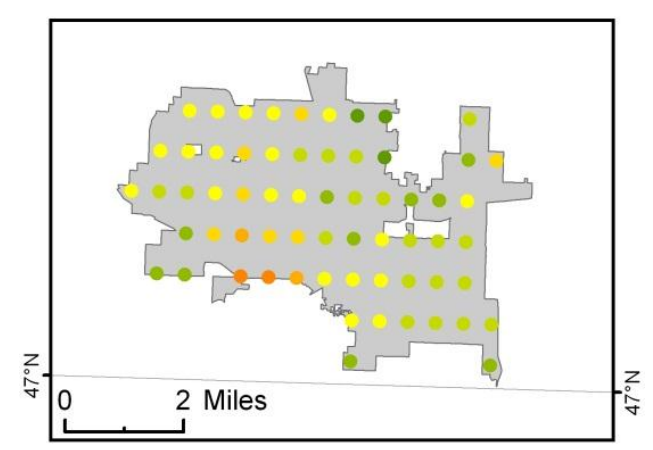

$$
\begin{array}{lllllllllll}
\bullet & \bullet & \bullet & \bullet & \bullet & 0 & \bullet & \bullet & \bullet & \bullet & \bullet \\
0 & -- & -- & -- & -- & 5 & - & -- & -- & - & 10
\end{array}
$$

Figure 11. Community-level spatial inconsistency index: a) Seattle; b) Olympia. Inconsistency ranges from dark green (no inconsistencies) up to red (ten inconsistencies).

a)

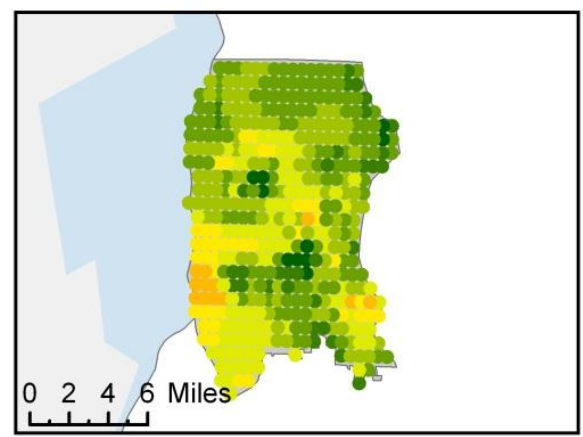

b)

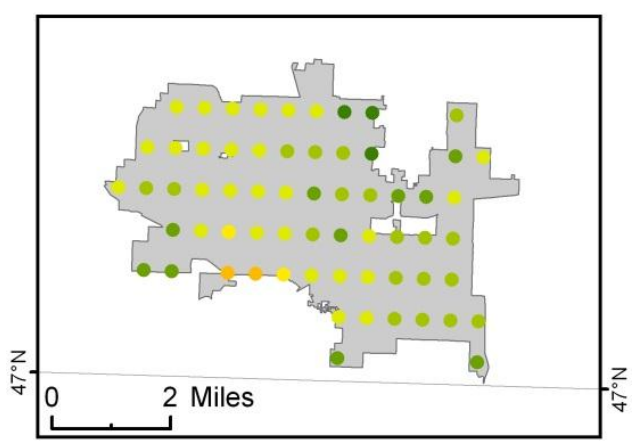

$$
\begin{array}{ccccccccc}
\bullet & \bullet & \bullet & \bullet & \bullet & \bullet & \bullet & \bullet & \bullet \\
\text { Low } & -- & -- & -- & \text { Med } & -- & -- & -- & \mathrm{Hi}
\end{array}
$$

Figure 12. Community-level inconsistency/count ratio index: a) Seattle; b) Olympia. Ratio ranges from dark green (inconsistencies infrequent compared to earthquakes) to red (inconsistencies frequent compared to earthquakes).

The mode number of inconsistent earthquakes for Seattle was three; the mode number of inconsistent earthquakes for Olympia was five (with an overall range of eleven, Olympia's mode of five was the least skewed frequency distribution of all analyzed areas). $34 \%$ of Seattle's sample points were affected by five or more earthquakes, and five or more earthquakes affected approximately 50\% of Olympia's 
sample points (once again showing that Olympia's earthquake sample frequency distribution was minimally skewed). Olympia had a smaller number of sample points because the community's total area was less than Seattle but the sample resolution was the same for both communities.

Because of the community level's large spatial scale, the differences between the inconsistency index (in Figure 11) and the inconsistency/count ratio index (in Figure 12) were minimal. Eleven or twelve earthquakes affected the entire area in each community, so varying relationships due to the number of earthquakes did not really show up. This demonstrated that the need for comparing the number of earthquakes to the number of inconsistencies varies depending on the scale research is being conducted at.

Spatial scale does appear to have an effect on how significant the discrepancies between MMI-grouped PGA classes and official MMI classes are. The population exposures varied from official MMI showing more exposure to MMI-grouped PGA showing greater exposure back to official MMI more frequently having the greater impact on exposure. Though the data did not always show these transitions in the same MMI classes, the transitions were almost always present.

The population exposures showed the pattern of greater official MMI exposure in low and high MMI classes and greater MMI-grouped PGA exposure in the middle MMI classes, but the spatial sampling tended to pick up more MMI-grouped PGA exposures in the highest MMI classes than the population exposure results did. Rather, MMI-grouped PGA dominance in the highest MMI classes was more visible in the spatial samples whereas the official MMI dominance in the highest MMI classes was more visible in the 
population exposures. This was related to how the data were observed and analyzed: the spatial version allowed the MMI-grouped PGA results to be more visible while the tabular version allowed the official MMI results to stand out. The type of MMI class data that dominated was interesting but unimportant: the fact that one was larger than the other showed that the two datasets were not closely matched to each other. MMI-grouped PGA data and official MMI data from ShakeMap are, based on the results detailed above, not interchangeable with each other for exposure assessments.

Both the exposure assessment and the sampling assessment determined that significant differences exist between MMI-grouped PGA data and official MMI data. A discussion of these differences relative to the data source helps put the results into perspective. Along with clarification regarding why the two versions of MMI are different, the issues encountered during the analysis are detailed. 


\section{Discussion}

The results of the exposure and sampling analyses both revealed differences between ShakeMap's MMI-grouped PGA data and official MMI data. PGA conversions to MMI commonly overestimated exposure in MMI classes relative to the exposure for the same MMI class in the official MMI data. This was not always the case, howeverfor example, the Cascadia and SWIF Southeast earthquakes both reported a small number of people exposed to MMI IX shaking when using the official MMI polygons compared to the PGA groups (which did not show any exposure to MMI IX shaking).

Paired exposure observations varied in their likelihood of greater exposures occurring in official MMI results compared to MMI-grouped PGA results. The overall trend in the exposure and sampling analyses showed that official MMI tended to be greater in the lowest and highest MMI classes, with MMI-grouped PGA results being greater in the middle MMI classes. Comparisons of the number of occurrences in the exposure data also suggested this trend - the results where both MMI-grouped PGA and official MMI had exposures tended to show more exposure in the grouped PGA data while the unpaired results were overwhelmingly greater for official MMI data. Since unpaired results were mostly in the low and high MMI classes, the fact that unpaired results were frequently greater for official MMI results was appropriate.

The dominance of MMI-grouped PGA exposure being greater than official MMI exposure was less obvious for the county- and community-level paired results than the state-level results; this was partly due to the fact that the overall range for these scales was smaller. The lower-middle MMI classes would have a greater impact and would be 
more likely to show greater exposure in official MMI classes than in MMI-grouped PGA classes. The unpaired results showed a large difference between the number of official MMI counts compared to MMI-grouped PGA counts. Generally the observations occurred in the low MMI classes, though a small number did occur in the high MMI classes. Tables 15 and 16 show summaries of the paired and unpaired exposures and which type of MMI data reported higher exposure.

Table 15. Summary of number and percentage of paired population exposure results from twelve earthquakes by scale

\begin{tabular}{lcccccc}
\cline { 2 - 7 } & \multicolumn{2}{c}{ Official MMI } & \multicolumn{2}{c}{ MMI-grouped PGA } & \multicolumn{2}{c}{ Equal } \\
\hline Scale & Count & Percent & Count & Percent & Count & Percent \\
\hline State $^{\mathrm{a}}$ & 19 & 38.78 & 30 & 61.22 & -- & -- \\
County $^{\mathrm{b}}$ & 31 & 52.54 & 28 & 47.46 & -- & -- \\
Community $^{\mathrm{c}}$ & 15 & 41.67 & 18 & 50.00 & 3 & 8.33 \\
\hline
\end{tabular}

a Total number of state-level comparisons: 49

${ }^{\mathrm{b}}$ Total number of county-level comparisons: 59

${ }^{\mathrm{c}}$ Total number of community-level comparisons: 36

Table 16. Summary of number and percentage of unpaired population exposure results from twelve earthquakes by scale

\begin{tabular}{lcccc} 
& \multicolumn{2}{c}{ Official MMI } & \multicolumn{2}{c}{ MMI-grouped PGA } \\
\hline Scale & Count & Percent & Count & Percent \\
\hline State $^{\text {a }}$ & 15 & 83.33 & 3 & 16.67 \\
County $^{\mathrm{b}}$ & 19 & 82.61 & 4 & 17.39 \\
Community $^{\mathrm{c}}$ & 12 & 70.59 & 5 & 29.41 \\
\hline
\end{tabular}

${ }^{\text {a }}$ Total number of state-level observations: 18

${ }^{\mathrm{b}}$ Total number of county-level observations: 23

${ }^{c}$ Total number of community-level observations: 17

As the scale of the spatial unit increased, the number of available earthquake exposure results for correlation comparison decreased. Table 17 shows a summary of how many exposure results were available for each MMI class at each scale. Though the 
county and community results were aggregated, the individual counties and communities followed the same pattern as their aggregate counterparts. Only King County even matched the number of state-level exposures (MMI V had the same exposure count for both the county and the state).

Table 17. Summary of exposure occurrence percentages from twelve earthquakes by MMI class and scale

\begin{tabular}{lccccc}
\hline Scale & MMI V & MMI VI & MMI VII & MMI VIII & MMI IX \\
\hline State $^{\mathrm{a}}$ & $100.00 \%$ & $100.00 \%$ & $100.00 \%$ & $83.33 \%$ & $58.33 \%$ \\
County $^{\mathrm{b}}$ & $83.33 \%$ & $83.33 \%$ & $66.67 \%$ & $29.17 \%$ & $12.50 \%$ \\
Community $^{\mathrm{b}}$ & $54.17 \%$ & $66.67 \%$ & $54.17 \%$ & $20.83 \%$ & $4.17 \%$ \\
\hline
\end{tabular}

a Total number of state-level occurrences: 12

${ }^{\mathrm{b}}$ Total number of county-level occurrences: 24

In addition to the impact scale had on the number of earthquakes available for correlation, all MMI classes with the exception of MMI VII had some earthquakes where exposure results were only available for one of the two datasets. MMI VII, being in the middle of the MMI class range, was the only class where all earthquakes had exposure in both types of MMI. This discrepancy influenced the overall correlation results. In the case of Seattle, only two samples were available for MMI VIII-the correlation was perfect in this case since no deviation from the trend line was possible with only two samples available for establishing correlation. Thurston County, on the other hand, had one sample where no official MMI exposure was recorded but MMI-grouped PGA exposure was and a second sample where no MMI-grouped PGA exposure was recorded but official MMI exposure was. Those two points combined with a sample where both MMI-grouped PGA and official MMI had exposure resulted in a very poor correlation. 
The correlation scatterplots for all five study regions for MMI classes V through IX and a combination of all five MMI classes are included in Appendix 3.

\section{ShakeMap and spatial differences}

The reasons for the differences between the MMI-grouped PGA results and the official MMI results relate to the programming built into ShakeMap and the level of detail ShakeMap's developers believed to be useful for outputs. ShakeMap uses a quartet of formulae to convert instrumental shaking (PGA, PGV) to perceived shaking (MMI). Depending on the result from one formula, either the second or the third/fourth will be used to generate a formal MMI value. This means that the PGA and MMI datasets are not mirror images of each other.

Wald et al. (1999) demonstrated in their analysis of historical California earthquakes that a perfect positive relationship between PGA or PGV and MMI does not exist. PGA levels out at some point during an earthquake, but PGV can continue to increase. Because PGA shaking plateaus during an earthquake, higher MMI values are calculated using PGV. The Washington research results partially illustrated the PGA plateau phenomenon by showing that in higher MMI classes MMI-grouped PGA classes were generally lower when they did not match the official MMI classes. In the lower MMI classes, MMI-grouped PGA was more likely to be higher than the official MMI. This is a result of how the formulae calculate MMI: for a PGA of $50 \mathrm{~cm} / \mathrm{s}^{2}$, the result of Formula (1) is 4.5 [3.66log $(50)-1.66]$. Since this returns an MMI class lower than V, Formula (3) is then used, producing a result of $4.7[2.20 \log (50)+1.00] .4 .7$ is slightly lower than the MMI V class the original PGA value of 50 falls in $(50 \mathrm{~cm} \div 100 \mathrm{~cm}=0.50$ 
$\mathrm{m} ; 0.50 \mathrm{~m} / \mathrm{s}^{2} \div 9.8 \mathrm{~m} / \mathrm{s}^{2}=0.05 \% \mathrm{~g}$ ), so the MMI-grouped PGA class would rank higher than the official MMI class.

Due to the fact that the sampling analysis compared the two MMI datasets to each other spatially rather than through exposure results, official MMI classes did not show up as being larger than MMI-grouped PGA classes where lower MMI classes occurred. This does not suggest that the earlier exposure-based results showed something different. If the MMI-grouped PGA class is higher for a series of samples, then the exposure at these points is necessarily in a lower MMI class in the official MMI data. Identifying the block-level population for each point for each type of MMI data and summarizing by MMI class would likely show the same trends as the overall exposure analysis.

Even when PGA and MMI classes may be close enough to minimize differences based on the original PGA and MMI values provided by ShakeMap in raster format, the vector ShakeMap outputs for GIS programs group PGA values into ranges of 0.04 , usually starting at 0.02 and increasing by 0.02 to 0.04 before using 0.04 intervals. The break value for PGA to identify MMI class IV is 0.039 . This value is extremely close to the PGA output of 0.04, but the next MMI break level is $0.092-0.012$ away from the closest corresponding PGA break (which is below the MMI break at 0.08 unlike the previous class whose break was 0.001 above). Once the reported MMI value is VIII then calculations are done using PGV rather than PGA, creating even more variation between MMI and PGA data. This could be verified by using ShakeMap's raster data instead of their vector data (the raster data are continuous rather than discrete), but using rasters introduces a different set of problems to compensate for. 


\section{Issues}

Several issues presented themselves during the course of this analysis. The issues all related to the available ShakeMap data. The first issue was data availability. The analysis required the same ShakeMap earthquake datasets as Wood \& Ratliff's exposure assessment since one of the interchangeability tests of the two MMI datasets was to compare the official MMI results to the PGA-based results from the 2010 Census update of Wood \& Ratliff's original USGS exposure analysis (Ratliff, Wood, \& Weaver, 2011). Though the majority of the original earthquakes were available on ShakeMap's web site, two earthquakes did not match the original data. The Cascadia and Seattle earthquakes varied significantly from the data used by USGS (the new data for Cascadia were not generalized as much as the older data, with the reverse being true for the Seattle Earthquake). These differences can be seen in Figure 13 below.

The difference between the original Seattle dataset and the new Seattle dataset may have simply been human error: a second Seattle Earthquake with the same magnitude generated in a different year was probably the scenario actually used for the USGS assessment. The Cascadia Earthquake, which may have been updated in response to the 2011 Tohoku Earthquake in Japan after Wood \& Ratliff's assessment, has since been removed, updated, and reloaded into ShakeMap's archive. Since MMI polygons were not used by USGS, the PGA polygons had to be reprocessed for the Cascadia and Seattle earthquakes so the PGA and MMI results could be consistently compared. The version of the earthquake data being used was unimportant so long as the same PGA and 
MMI data were processed to allow appropriate identification of differences between MMI-grouped PGA data and official MMI data.

a)

c)
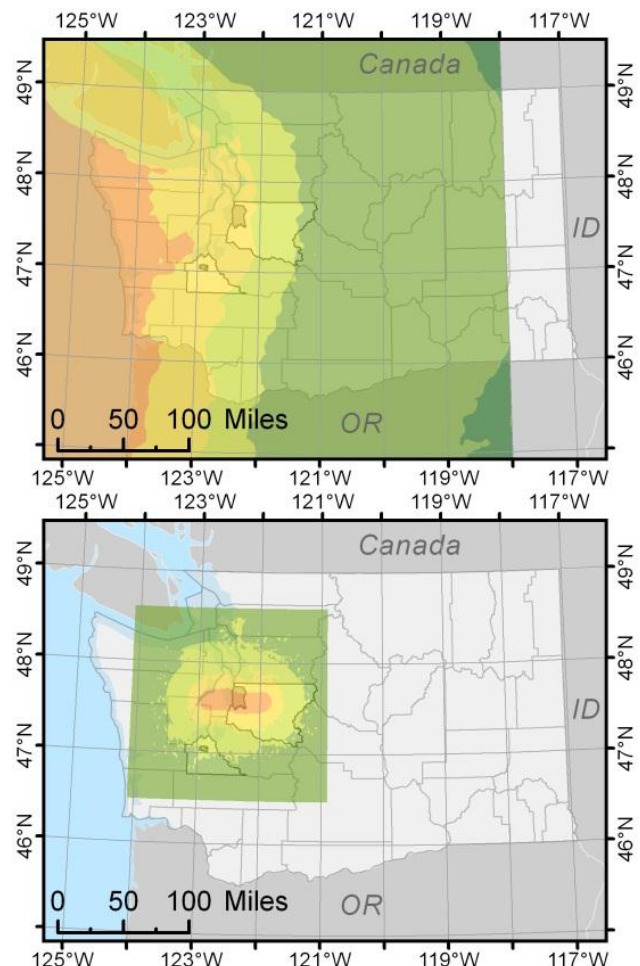

b)

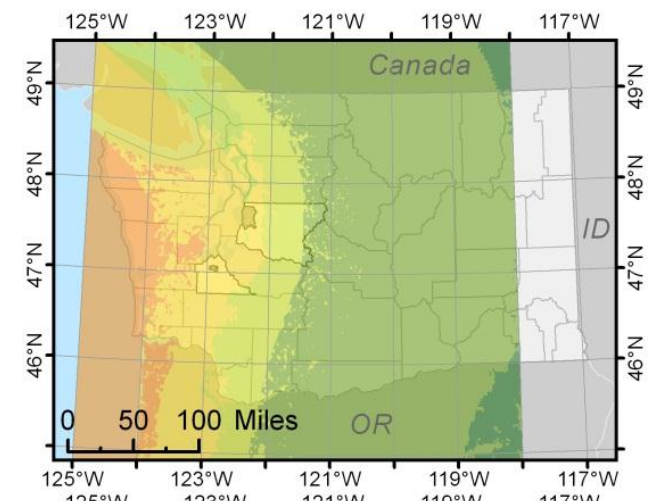

d)

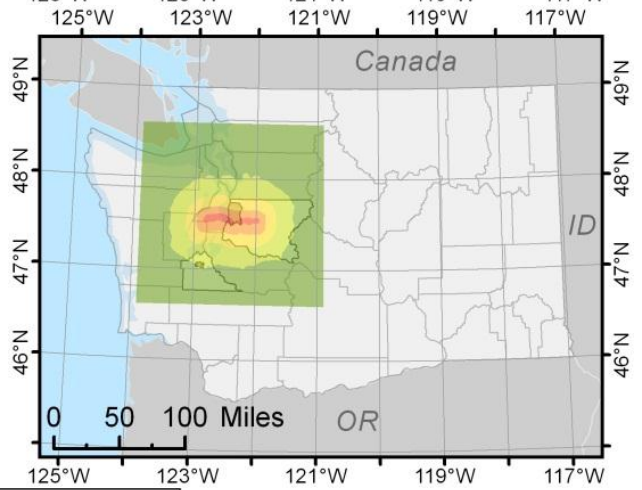

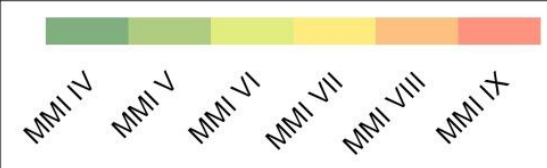

Figure 13. Variations between original and new Cascadia and Seattle earthquake data: a) original Cascadia PGA data; b) new Cascadia PGA data; c) original Seattle PGA data; d) new Seattle PGA data.

One of the other issues with ShakeMap's data that surfaced during the exposure assessment process was related to the polygons in the official MMI data file. Four of the twelve earthquakes analyzed (three scenarios and the one historical) reported flawed demographic values when state totals were established after merging the shaking and demographic data. An evaluation of the original MMI data using the topology tools in ArcMap revealed that some areas had multiple polygons covering the same spatial area. 
One example of this issue can be seen in Figure 14-the multiple entries for the Cascadia_M9_0_mmi dataset show that three polygons are covering the same spatial area as the smallest center polygon.

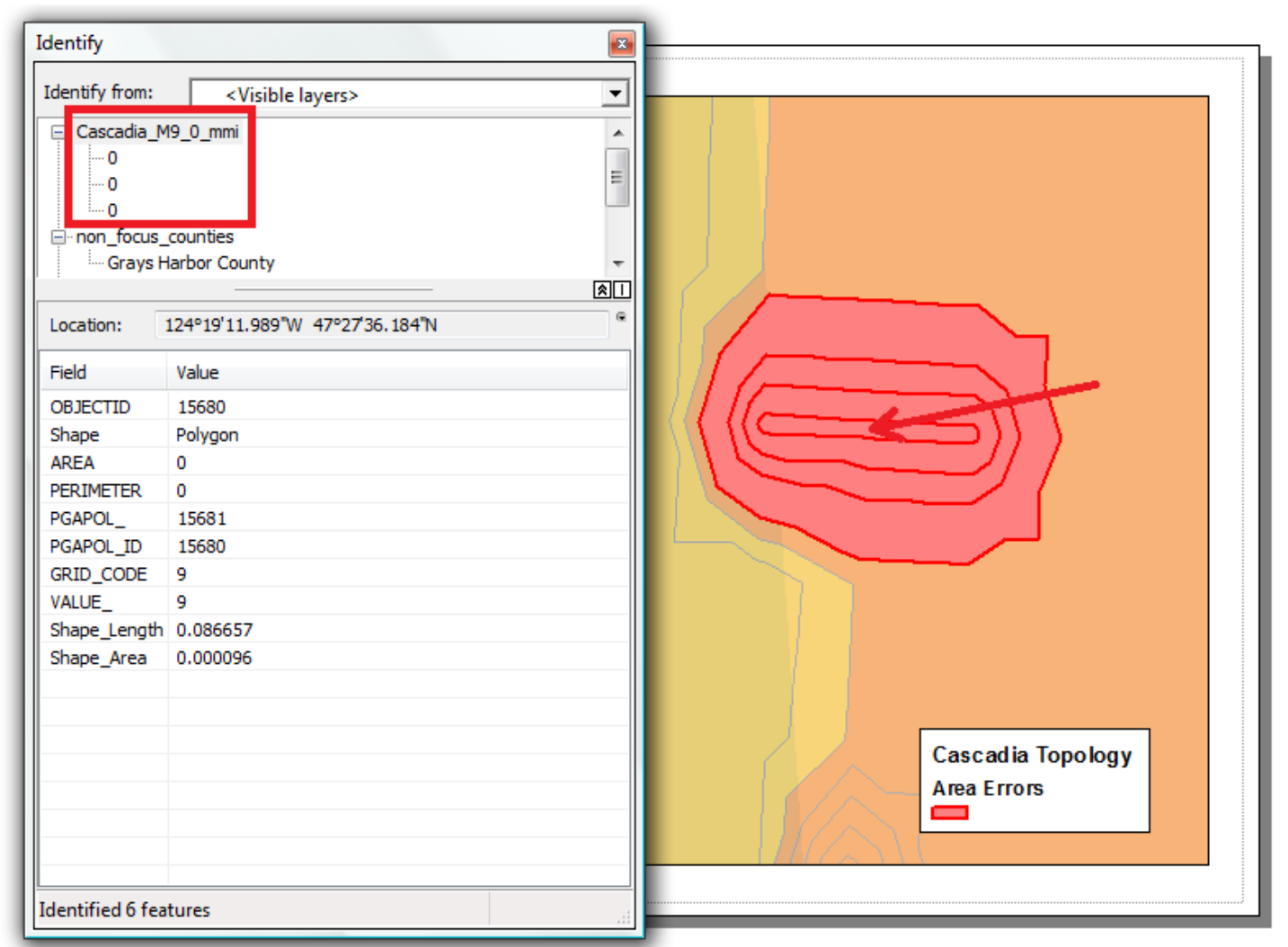

Figure 14. Polygon overlap data error in Cascadia Earthquake MMI data. The red arrow points out where the dialog to the left is referring to, and the red box in the upper left of the dialog shows three entries representing each of the polygons that overlap at the arrow's location.

Errors in the original MMI data were not the only cause for the inaccurate demographic totals. In certain scenarios when the Census block data and MMI earthquake data were merged, the merge created additional polygons in the resulting datasets in locations where polygon overlaps did not previously exist. This problem was verified by summarizing the original and ratio demographic attributes of the datasets in 
Excel to find any blocks returning ratio summaries greater than the original block value (e.g., the ratio sum for the block was 8 when the actual value for the block was 4).

After additional assessment of the original MMI polygon data and the merged output, the high level of detail in both the MMI polygons and the Census block data was identified as a potential cause for the unexpected polygon duplication. The MMI polygon data were aggregated to determine if the level of detail was actually the problem's origin. Aggregate MMI data represented only the major MMI classes (3, 4, 5, etc.) rather than the original decimal intensity classes $(3,3.2,3.4$, etc.). Exposures from the generalized MMI datasets were unchanged in areas where polygon replication had not occurred and were corrected in areas where discrepancies existed. One exception to this was the historical Nisqually Earthquake - this earthquake lost a small number of polygons in the generalized MMI VII class; this was corrected for in post-processing since the missing data were all in the same MMI class. Polygon replication did not occur with the PGA data, which was likely due to ShakeMap generalizing the polygon PGA data by default.

A final concern that surfaced during the analysis was the fact that the total exposure for the PGA and MMI datasets did not initially match (e.g., Lake Creek Earthquake exposed population: 4,228,482 PGA and 4,238,767 MMI—a difference of 10,285 people [approximately $0.41 \%$ ]). This discrepancy occurred as a result of how the GIS software spatially transformed the datasets from one coordinate system to another. Though both the PGA and MMI data started in the same geographic coordinate system and were transformed to the same projected coordinate system, the two datasets transformed slightly differently on the northern and southern edges. 
ShakeMap's MMI spatial data were more detailed than the PGA spatial data. The greater detail in the MMI data led to more points (vertices) along the modeled earthquake boundaries. With more vertices available in the MMI spatial data, the MMI data were able to more accurately transform, or conform, to the projected coordinate system from the geographic coordinate system than the PGA data. This resulted in the MMI data extending farther south on both the northern and southern edges of the spatial data than the PGA data extended.

In the Lake Creek Earthquake, the southern boundary was crossing through Olympia; the extension south for MMI relative to PGA meant that more people residing in Olympia were exposed to MMI shaking than to PGA shaking according to the GIS software. Figure 15 shows the discrepancy between the projected MMI and PGA spatial data for the Lake Creek Earthquake.

a)

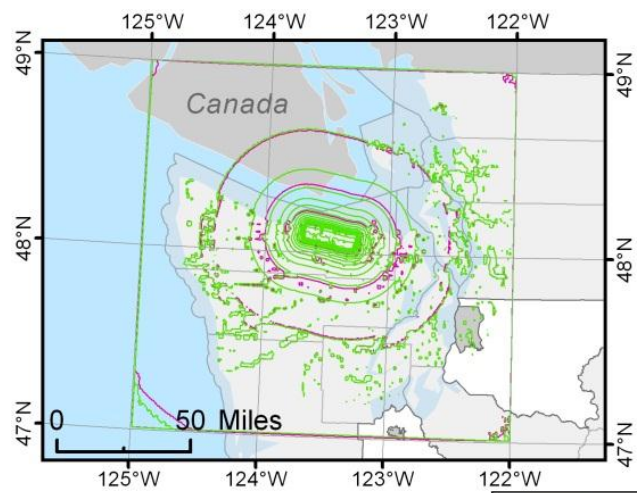

b)

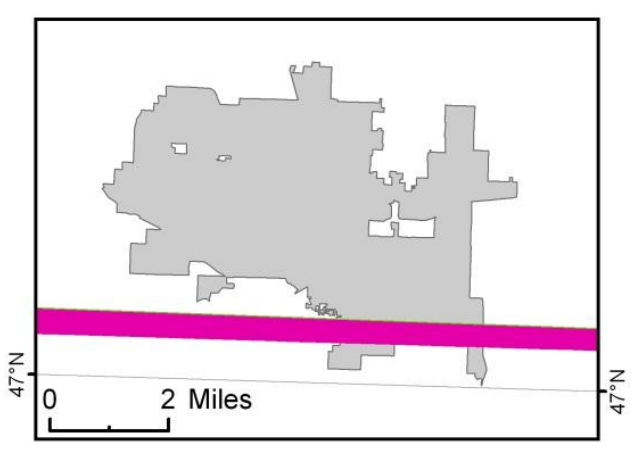

PGA $\square$ MMI

Figure 15. Boundary discrepancy in projected PGA and MMI ShakeMap data. The two images show: a) the full extent of the Lake Creek Earthquake, with the northern and southern boundaries not perfectly matching; and b) the spatial difference between PGA and MMI relative to the Olympia city boundary (shown as a magenta band representing where MMI data was available but not PGA data).

Not all scenarios were significantly different between the MMI and PGA exposure results. The SeaTac Earthquake only had a population difference of 14 (4,304,473 MMI 
and 4,304,459 PGA), and the Cascadia and Cascadia North earthquakes reported no difference at all $(6,129,661$ in both PGA and MMI). Cascadia and Cascadia North had no discrepancies since the inconsistent northern and southern edges of the study area fell outside of the state.

By merging the ShakeMap and demographic data in ShakeMap's original latitude/longitude geographic coordinate system rather than the projected coordinate system intended for the final analysis, the north/south distortions were prevented and the same total exposures were found. Areas needed to be calculated to permit dividing demographics between MMI classes, so projecting the data was necessary. The data were simply projected after any data merging to accommodate both the need to keep the study areas consistent between datasets and the need to calculate exposures based on area.

Regardless of the concerns specified above, both the MMI data and PGA data can provide valuable insights into how people could potentially be affected by an earthquake as long as the problems possible with the data are known and compensated for when possible. Exposure assessments are not intended to be used as definitive representation of affected variables since no model or assessment can truly predict what areas will experience what level of shaking or where people actually are. Exposure assessments should be used as general guides rather than the absolute truth. These results do not say that one dataset should be used for exposure assessment rather than the other; they simply demonstrate that the two datasets are significantly different spatially and are not interchangeable based on these spatial differences. 


\section{Conclusion}

Two different components of the USGS ShakeMap Project's earthquake shaking data were compared to determine whether they could be used interchangeably for exposure analyses. Modified Mercalli Intensity (MMI) data and peak ground acceleration (PGA) data aggregated to approximate MMI were both analyzed to determine the difference in demographic exposure as well as the spatial difference between MMI classes in the two datasets. The analysis was conducted at three spatial scales: the state level, the county level, and the community level. Results indicated that grouping PGA data from ShakeMap into MMI classes did not directly correspond to ShakeMap's official MMI classes. The implications of this inconsistency varied depending on the spatial scale of the exposure analysis.

The inconsistency between MMI-grouped PGA data and official MMI data was not linear. More data in the possible lower MMI classes tended to be overestimated when converting PGA to MMI, and more data in the potential higher MMI classes were underestimated when converting PGA to MMI. These over- and under-estimates were also not consistent: some earthquakes reported MMI-grouped PGA exposure in MMI class IX when official MMI data did not.

Scale did have an effect on the trends seen in the exposure and sampling analyses. The state level, as the smallest scale, had the most data to work with, the most variation in inconsistency present, and the highest number of significant differences between sample MMI class means. Significant differences were also extremely common at the county and community scales, but Thurston County and Olympia both had one 
earthquake show insignificant differences between MMI class means. Olympia had an additional pair of earthquakes with less (but still) significant differences. This showed that scale may have a small effect on the likelihood that the differences between MMIgrouped PGA classes and official MMI classes could impact an exposure assessment.

Scale was not the only aspect that seemed to affect the significance of the sampling results. One of the side tests for the research was to determine if a difference was visible between scenario and historical earthquakes: the county and community samples had insignificant differences between the two types of MMI for the historical earthquake, unlike any of the scenario earthquakes run. This suggests that the type of earthquake potentially has an effect, but since only one historical earthquake was analyzed this observation should be kept in context.

Future research that could be done to expand on the results of this analysis consists of three options: assess raster inputs in place of vector polygon inputs, incorporate PGV into the analysis and verify its relationship with PGA and MMI, and introduce additional historical earthquakes to see if the pattern of insignificance reasserts itself in other historical events compared to scenario events. Replacing the polygon data used here with raster data could permit a more accurate exposure assessment both in the MMI-grouped PGA data and the official MMI data since the rasters available from ShakeMap are far more detailed and precise than the polygon data. Adding in PGV to the PGA and MMI comparison would further confirm or disprove the interchangeability of the various ShakeMap outputs. Finally, since the one historical earthquake showed that scale rendered the differences between MMI-grouped PGA classes and official MMI 
classes insignificant at some scales, processing additional historical earthquakes would help see whether this is simply random or not. If historical earthquake data do more accurately pick up significance (or lack thereof) at large scales, then perhaps this could be incorporated into ShakeMap's model to improve their scenario earthquake data.

Exposure quantifies how society could be affected by a disaster. Vulnerability takes those quantities and augments them with insights that customize the analysis for the group being examined. The spatial aspect of exposure and vulnerability is yet another thing to consider when planning for emergencies. With vulnerability being in part an examination of spatiality, knowing as much as possible about the group and area being studied will help emergency planners and managers mitigate disaster damages more effectively and efficiently. 


\section{References}

Alcántara-Ayala, I. (2002). Geomorphology, natural hazards, vulnerability and prevention of natural disasters in developing countries. Geomorphology, 47, 107124.

Bankoff, G., Frerks, G., and Hilhorst, D. (Eds.). (2004). Mapping Vulnerability: Disasters, Development, and People. Sterling, VA: Earthscan Publications.

Birkmann, J. \& Wisner, B. (2006). Measuring the Un-Measurable: The Challenge of Vulnerability. Retrieved from http://www.ehs.unu.edu/article/read/278

Cross, J.A. (2001). Megacities and small towns: different perspectives on hazard vulnerability. Environmental Hazards, 3, 63-80.

Delor, F. \& Hubert, M. (2000). Revisiting the concept of 'vulnerability.' Social Science \& Medicine, 50, 1557-1570.

Federal Emergency Management Agency (FEMA). (2010). FEMA: DPA Glossary of Terms. Retrieved from http://www.fema.gov/about/programs/dpa/terms.shtm

Federal Emergency Management Agency (FEMA). 2012. FEMA: Hazus. Retrieved from http://www.fema.gov/plan/prevent/hazus/

Frazier, T.G., Wood, N., Yarnal, B., \& Bauer, D.H. (2010). Influence of potential sea level rise on societal vulnerability to hurricane storm-surge hazards, Sarasota County, Florida. Applied Geography, 30, 490-505.

Füssel, H-M. (2007). Vulnerability: A generally applicable conceptual framework for climate change research. Global Environmental Change, 17, 155-167.

Linnekamp, F., Koedam, A., \& Baud, I.S.A. (2011). Household vulnerability to climate change: Examining perceptions of households of flood risks in Georgetown and Paramaribo. Habitat International, 35, 447-456.

McLaughlin, P. \& Dietz, T. (2008). Structure, agency and environment: Toward an integrated perspective on vulnerability. Global Environmental Change, 18, 99111.

Ratliff, J., Wood, N. \& Weaver, C. (2011, December). Community Exposure and Sensitivity to Earthquake Hazards in Washington State. Poster session presented at the annual conference of the American Geophysical Union, San Francisco, CA.

Uitto, J. (1998). The geography of disaster vulnerability in megacities. Applied Geography, 18, 7-16. 
U.S. Census Bureau. (2011a). King County QuickFacts from the US Census Bureau. Retrieved from http://quickfacts.census.gov/qfd/states/53/53033.html

U.S. Census Bureau. (2011b). Olympia (city) QuickFacts from the US Census Bureau. Retrieved from http://quickfacts.census.gov/qfd/states/53/5351300.html

U.S. Census Bureau. (2011c). Seattle (city) QuickFacts from the US Census Bureau. Retrieved from http://quickfacts.census.gov/qfd/states/53/5363000.html

U.S. Census Bureau. (2011d). Thurston County QuickFacts from the US Census Bureau. Retrieved from http://quickfacts.census.gov/qfd/states/53/53067.html

U.S. Census Bureau. (2011e). Washington counties, places, and blocks [Data files]. Available from http://www.census.gov/geo/www/tiger/tgrshp2010/tgrshp2010.html

U.S. Census Bureau. (2011f). Washington QuickFacts from the US Census Bureau. Retrieved from http://quickfacts.census.gov/qfd/states/53000.html

U.S. Census Bureau. (2011g). Washington population and occupied housing units [Data files]. Available from http://www2.census.gov/census_2010

U.S. Geological Survey (USGS). (2011a). ShakeMap Scientific Background. Retrieved from http://earthquake.usgs.gov/earthquakes/shakemap/background.php

U.S. Geological Survey (USGS). (2011b). ShakeMap earthquake shaking data [Data files]. Available from http://earthquake.usgs.gov/earthquakes/shakemap/

U.S. House of Representatives, Committee on Transportation and Infrastructure. (2006). "Disasters and the Department of Homeland Security: Where do we go from here?" U.S. Government Printing Office: Washington, D.C.

Wald, D.J., Quitoriano, V., Heaton, T.H., \& Kanamori, H. (1999). Relationships between Peak Ground Acceleration, Peak Ground Velocity, and Modified Mercalli Intensity in California. Earthquake Spectra, 15, 557-564.

Wald, D.J., Worden, B.C., Quitoriano, V., \& Pankow, K.L. (2006). ShakeMap Manual: Technical Manual, Users Guide, and Software Guide. Retrieved from http://pubs.usgs.gov/tm/2005/12A01/

Washington State Department of Natural Resources. (2012). Earthquakes in Washington. Retrieved from http://www.dnr.wa.gov/researchscience/topics/geologichazardsmapping/pages/ear thquakes.aspx 
Williamson, T., Hesseln, H., \& Johnston, M. (2012). Adaptive capacity deficits and adaptive capacity of economic systems in climate change vulnerability assessment. Forest Policy and Economics, 15, 160-166.

Wisner, B., Blaikie, P., Cannon, T., and Davis, I. (Eds.). (2004). At Risk: Natural Hazards, People's Vulnerability and Disasters. New York, NY: Routledge.

Wood, N. (2009). Tsunami exposure estimation with land-cover data: Oregon and the Cascadia Subduction zone. Applied Geography, 29, 158-170.

Wood, N. (2011). Understanding Risk and Resilience to Natural Hazards. Retrieved from http://pubs.usgs.gov/fs/2011/3008/

Wood, N. \& Ratliff, J. (2011). Population and Business Exposure to Twenty Scenario Earthquakes in the State of Washington. Retrieved from http://pubs.usgs.gov/of/2011/1016/

Wood, N. \& Soulard, C. (2009). Variations in population exposure and sensitivity to lahar hazards from Mount Rainier, Washington. Journal of Volcanology and Geothermal Research, 188, 367-378. 
Appendix 1. The Modified Mercalli Intensity Scale (reprinted with permission from Wood \& Ratliff, 2011)

\begin{tabular}{|c|c|c|}
\hline MMI Class & PGA Range & Description of Societal Impact \\
\hline $\mathrm{I}$ & $<0.0017 \mathrm{~g}$ & $\begin{array}{l}\text { Not felt except by a very few under especially } \\
\text { favorable conditions. }\end{array}$ \\
\hline II & $0.0017-0.014 \mathrm{~g}$ & $\begin{array}{l}\text { Felt only by a few persons at rest, especially on upper } \\
\text { floors of buildings. }\end{array}$ \\
\hline III & $0.0017-0.014 \mathrm{~g}$ & $\begin{array}{l}\text { Felt quite noticeably by persons indoors, especially on } \\
\text { upper floors of buildings. Many people do not } \\
\text { recognize it as an earthquake. Standing motor cars } \\
\text { may rock slightly. Vibrations similar to the passing of } \\
\text { a truck. Duration estimated. }\end{array}$ \\
\hline IV & $0.014-0.039 \mathrm{~g}$ & $\begin{array}{l}\text { Felt indoors by many, outdoors by few during the day. } \\
\text { At night, some awakened. Dishes, windows, doors } \\
\text { disturbed; walls make cracking sound. Sensation like } \\
\text { heavy truck striking building. Standing motor cars } \\
\text { rocked noticeably. }\end{array}$ \\
\hline $\mathrm{V}$ & $0.039-0.092 \mathrm{~g}$ & $\begin{array}{l}\text { Felt by nearly everyone; many awakened. Some } \\
\text { dishes, windows broken. Unstable objects overturned. } \\
\text { Pendulum clocks may stop. }\end{array}$ \\
\hline VI & $0.092-0.18 \mathrm{~g}$ & $\begin{array}{l}\text { Felt by all, many frightened. Some heavy furniture } \\
\text { moved; a few instances of fallen plaster. Damage } \\
\text { slight. }\end{array}$ \\
\hline VII & $0.18-0.34 \mathrm{~g}$ & $\begin{array}{l}\text { Damage negligible in buildings of good design and } \\
\text { construction; slight to moderate in well-built ordinary } \\
\text { structures; considerable damage in poorly built or } \\
\text { badly designed structures; some chimneys broken. }\end{array}$ \\
\hline VIII & $0.34-0.65 \mathrm{~g}$ & $\begin{array}{l}\text { Damage slight in specially designed structures; } \\
\text { considerable damage in ordinary substantial buildings } \\
\text { with partial collapse. Damage great in poorly built } \\
\text { structures. Fall of chimneys, factory stacks, columns, } \\
\text { monuments, walls. Heavy furniture overturned. }\end{array}$ \\
\hline IX & $0.65-1.24 \mathrm{~g}$ & $\begin{array}{l}\text { Damage considerable in specially designed structures; } \\
\text { well-designed frame structures thrown out of plumb. } \\
\text { Damage great in substantial buildings, with partial } \\
\text { collapse. Buildings shifted off foundations. }\end{array}$ \\
\hline $\mathrm{X}$ & $>1.24 \mathrm{~g}$ & $\begin{array}{l}\text { Some well-built wooden structures destroyed; most } \\
\text { masonry and frame structures destroyed with } \\
\text { foundations. Rails bent. }\end{array}$ \\
\hline
\end{tabular}


Appendix 2. Selected ShakeMap earthquakes—basic statistics

\begin{tabular}{|c|c|c|c|c|}
\hline \multirow[b]{2}{*}{ Earthquake } & \multicolumn{2}{|c|}{ MMI Range } & \multicolumn{2}{|c|}{ Demographics (2010) } \\
\hline & PGA* & MMI** & Population & Percent \\
\hline Cascadia M9.0 & IV-VIII & III-IX & $6,129,662$ & $91.15 \%$ \\
\hline Cascadia North M8.3 & IV-VIII & I-VIII & $6,129,662$ & $91.15 \%$ \\
\hline $\begin{array}{l}\text { South Whidbey Island } \\
\text { Fault (SWIF) M7.4 }\end{array}$ & IV-IX & III-IX & $4,660,831$ & $69.31 \%$ \\
\hline SWIF Southeast M7.2 & $\mathrm{V}-\mathrm{VIII}$ & IV-IX & $4,450,517$ & $66.18 \%$ \\
\hline Seattle M7.2 & $\mathrm{V}-\mathrm{IX}$ & IV-VIII & $4,412,180$ & $65.61 \%$ \\
\hline Nisqually M6.8 & IV-VIII & III-VIII & $4,374,848$ & $65.06 \%$ \\
\hline Tacoma M7.1 & $\mathrm{V}-\mathrm{IX}$ & IV-IX & $4,345,390$ & $64.62 \%$ \\
\hline SeaTac M7.2 & $\mathrm{V}-\mathrm{VII}$ & IV-VII & $4,304,453$ & $64.01 \%$ \\
\hline Nisqually M7.2 & $\mathrm{V}-\mathrm{VII}$ & IV-VII & $4,241,482$ & $63.07 \%$ \\
\hline Lake Creek M6.8 & IV-IX & III-VIII & $4,238,818$ & $63.04 \%$ \\
\hline Canyon River M7.4 & $\mathrm{V}-\mathrm{IX}$ & IV-IX & $4,209,309$ & $62.60 \%$ \\
\hline Olympia M5.7 & $\mathrm{V}-\mathrm{VIII}$ & III-VII & $1,461,174$ & $21.73 \%$ \\
\hline
\end{tabular}




\section{Appendix 3. MMI-grouped PGA vs. MMI population exposure correlations}

\section{State MMI class exposure correlations}

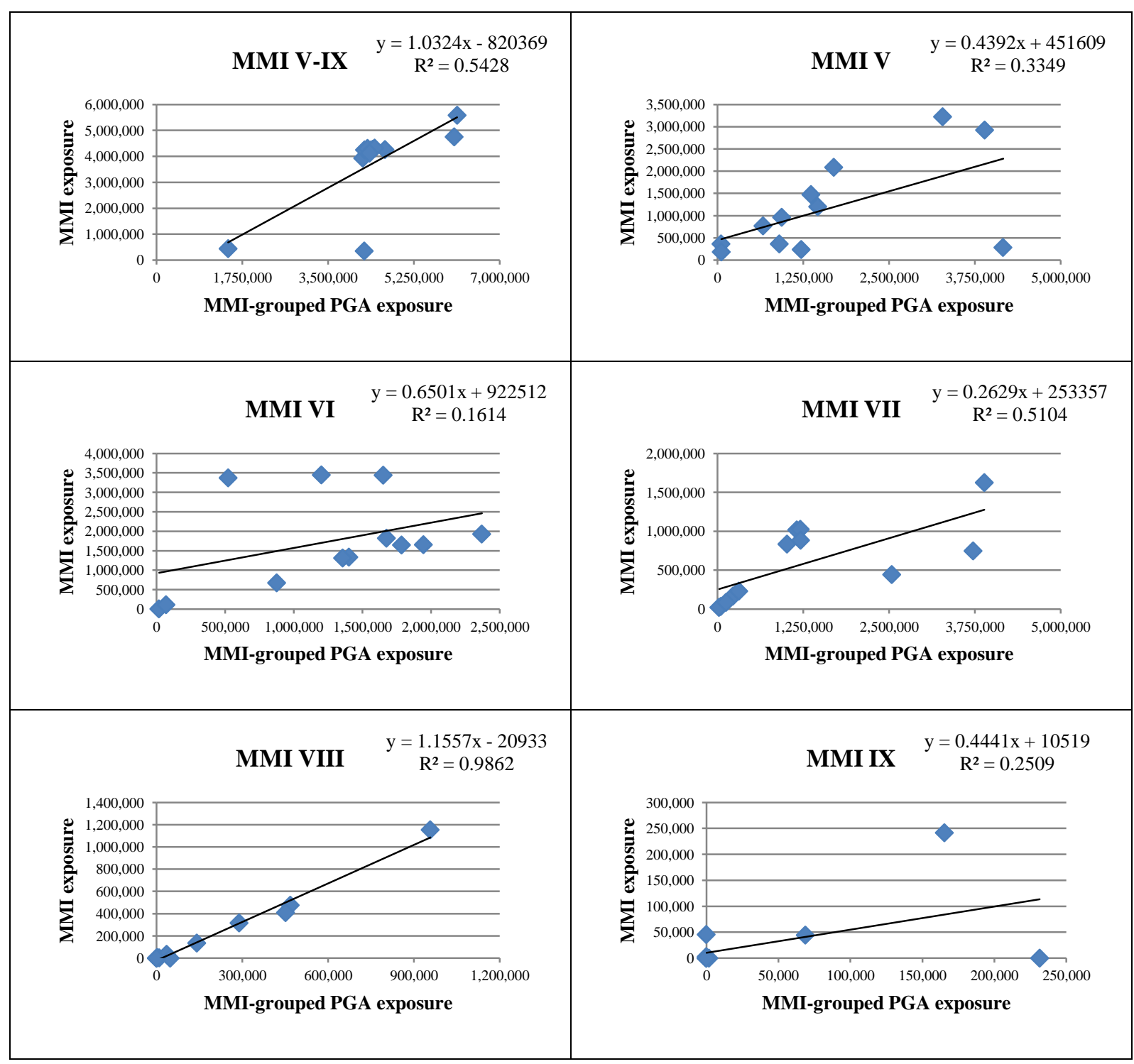

- Individual earthquake population exposure 
King County MMI class exposure correlations

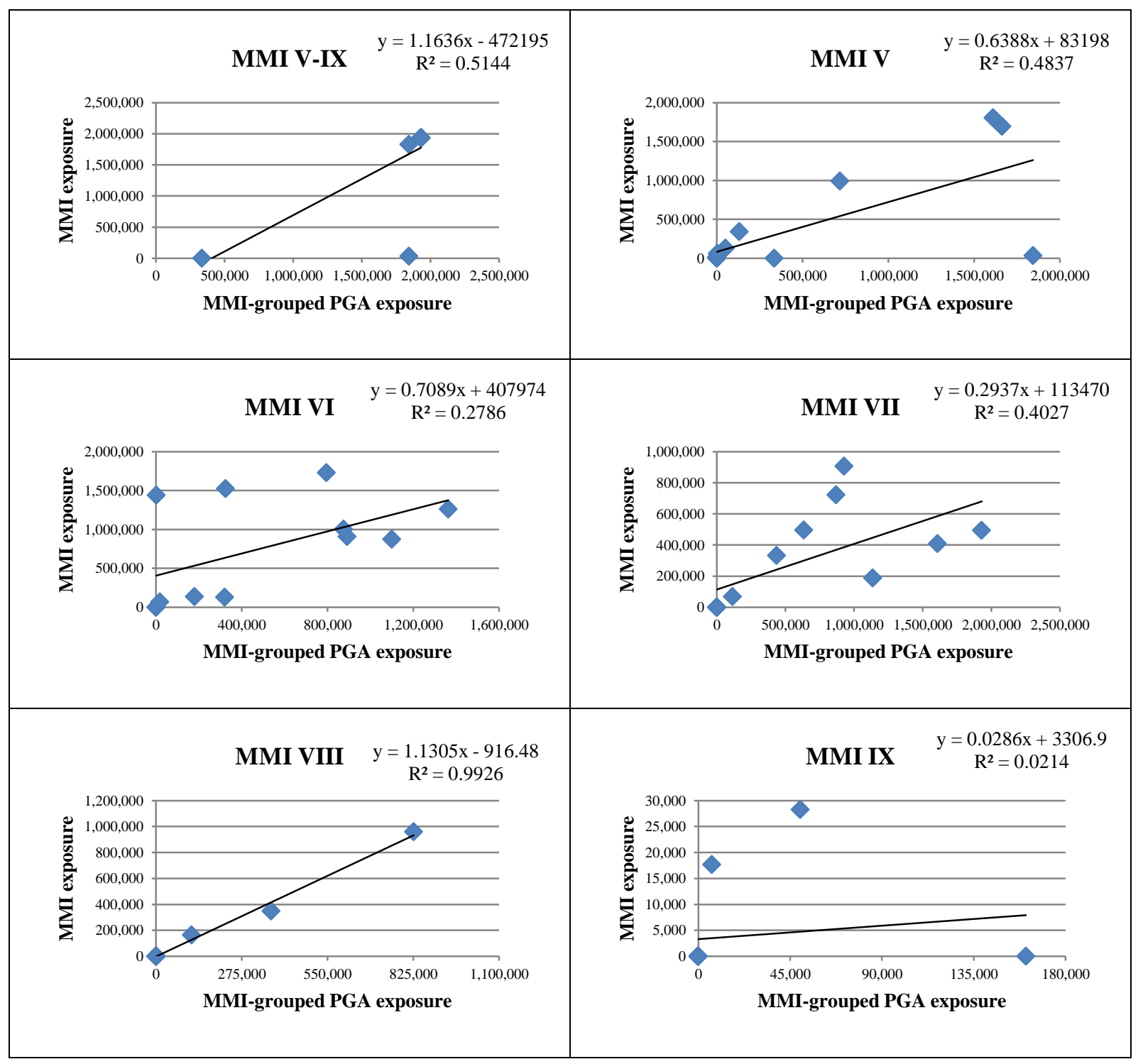

- Individual earthquake population exposure 
Thurston County MMI class exposure correlations

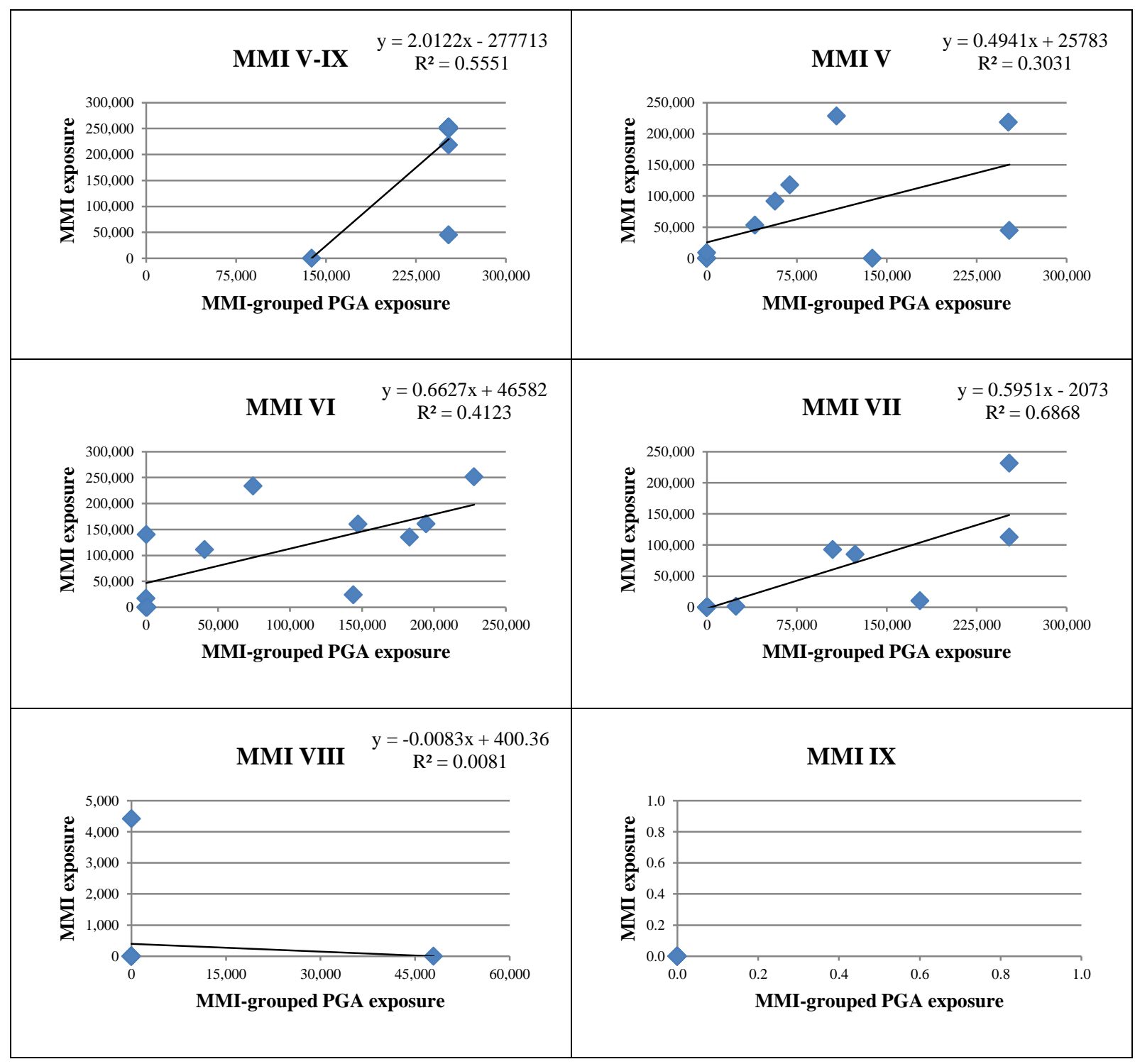

- Individual earthquake population exposure 
Seattle city MMI class exposure correlations

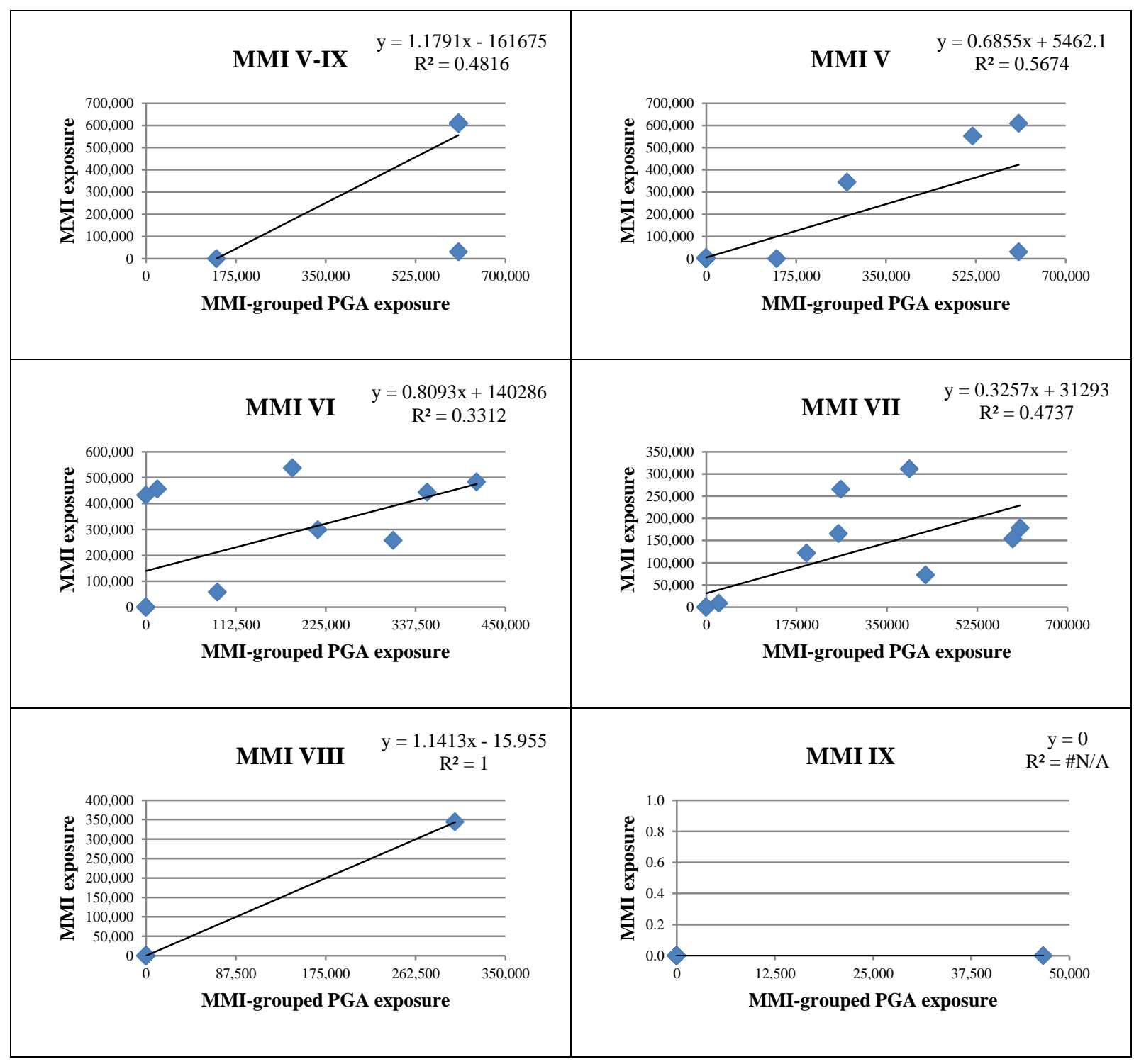

- Individual earthquake population exposure 


\section{Olympia city MMI class exposure correlations}

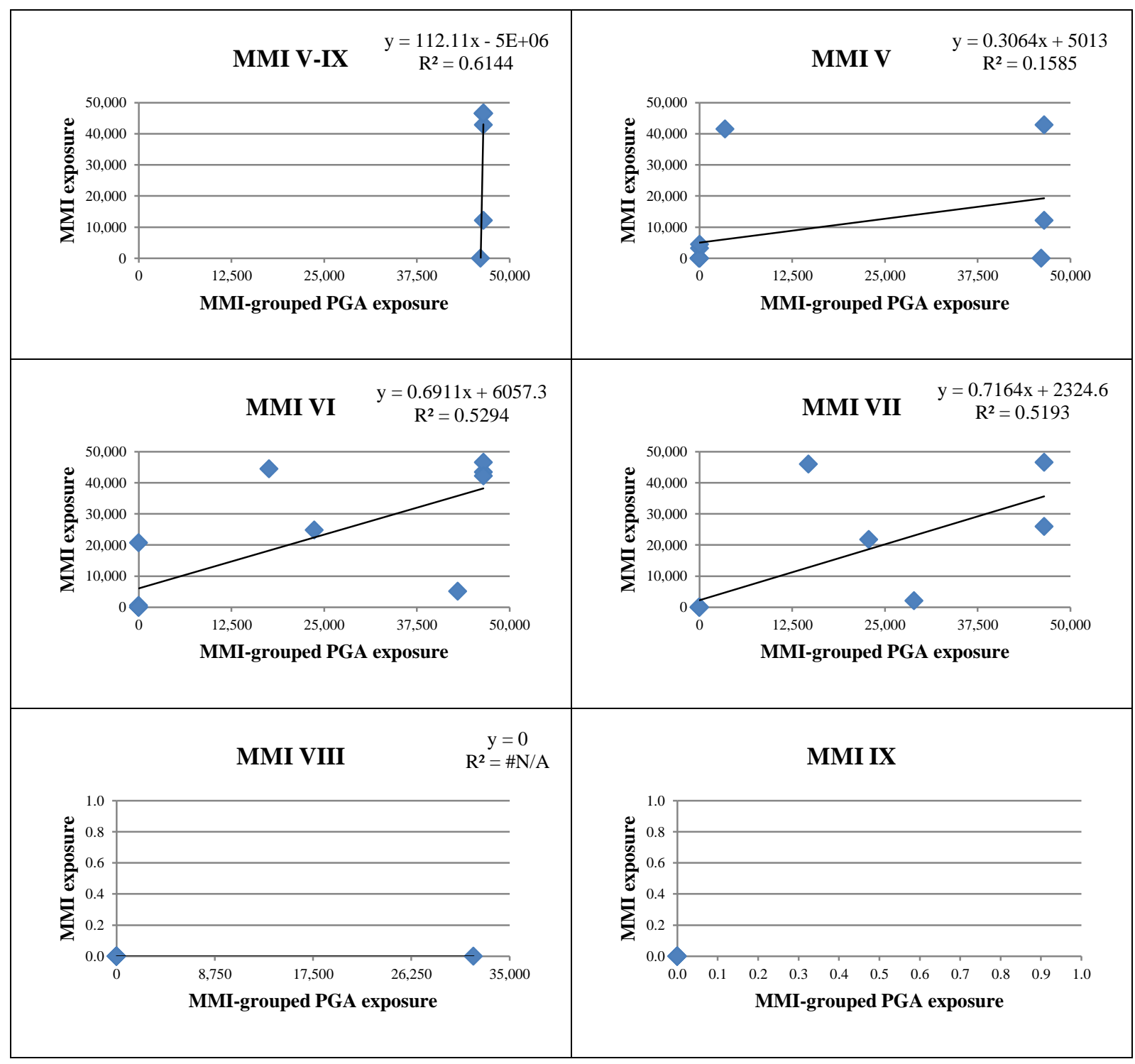

- Individual earthquake population exposure 
Appendix 4. Inconsistency index frequency distributions

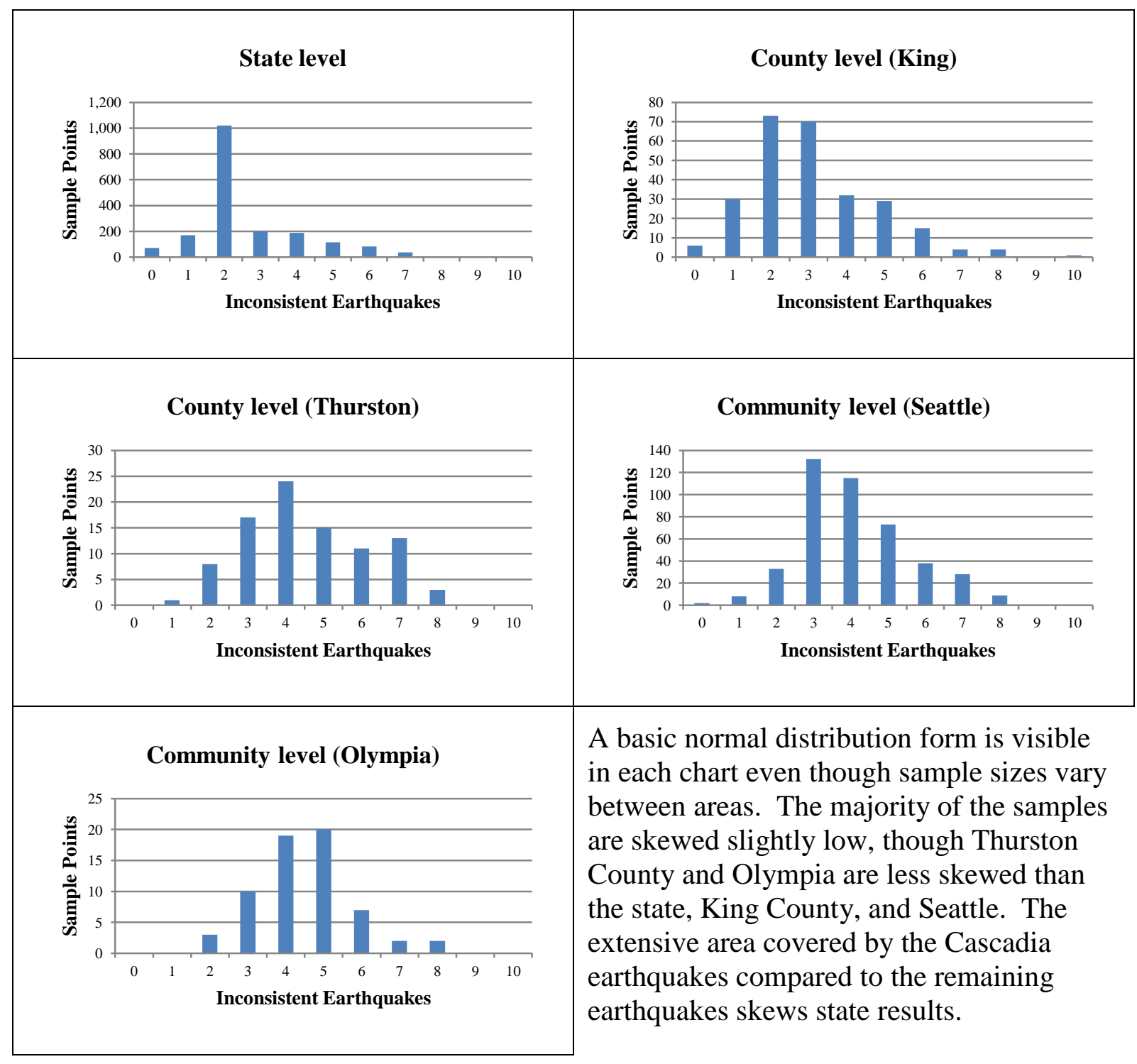


Appendix 5. Detailed statistics for spatial analyses

State-level MMI-grouped PGA descriptive statistics by earthquake

\begin{tabular}{lccccc}
\hline Earthquake & Mean & Median & Mode & $\begin{array}{c}\text { Standard } \\
\text { Deviation }\end{array}$ & $\begin{array}{c}\text { Sample } \\
\text { Variance }\end{array}$ \\
\hline Canyon River & 1.35 & 0 & 0 & 2.37 & 5.60 \\
Cascadia & 5.72 & 5 & 5 & 0.99 & 0.98 \\
Cascadia North & 5.05 & 5 & 5 & 0.73 & 0.54 \\
Lake Creek & 1.15 & 0 & 0 & 2.19 & 4.80 \\
Nisqually (h) & 1.89 & 0 & 0 & 2.58 & 6.65 \\
Nisqually & 1.78 & 0 & 0 & 2.73 & 7.45 \\
Olympia & 0.36 & 0 & 0 & 1.33 & 1.78 \\
SeaTac & 1.83 & 0 & 0 & 2.75 & 7.54 \\
Seattle & 1.67 & 0 & 0 & 2.57 & 6.61 \\
SWIF & 2.31 & 0 & 0 & 2.73 & 7.43 \\
SWIF Southeast & 1.85 & 0 & 0 & 2.62 & 6.84 \\
Tacoma & 1.65 & 0 & 0 & 2.50 & 6.26 \\
\hline
\end{tabular}

State-level MMI descriptive statistics by earthquake

\begin{tabular}{lccccc}
\hline Earthquake & Mean & Median & Mode & $\begin{array}{c}\text { Standard } \\
\text { Deviation }\end{array}$ & $\begin{array}{c}\text { Sample } \\
\text { Variance }\end{array}$ \\
\hline Canyon River & 1.25 & 0 & 0 & 2.23 & 4.95 \\
Cascadia & 5.16 & 5 & 4 & 1.20 & 1.44 \\
Cascadia North & 4.30 & 4 & 4 & 1.04 & 1.08 \\
Lake Creek & 1.00 & 0 & 0 & 1.92 & 3.69 \\
Nisqually (h) & 1.79 & 0 & 0 & 2.46 & 6.05 \\
Nisqually & 1.66 & 0 & 0 & 2.54 & 6.43 \\
Olympia & 0.31 & 0 & 0 & 1.15 & 1.31 \\
SeaTac & 1.70 & 0 & 0 & 2.55 & 6.49 \\
Seattle & 1.53 & 0 & 0 & 2.39 & 5.73 \\
SWIF & 2.07 & 0 & 0 & 2.51 & 6.30 \\
SWIF Southeast & 1.72 & 0 & 0 & 2.49 & 6.20 \\
Tacoma & 1.48 & 0 & 0 & 2.29 & 5.22 \\
\hline
\end{tabular}


County-level MMI-grouped PGA descriptive statistics by earthquake: King County

\begin{tabular}{lccccc}
\hline Earthquake & Mean & Median & Mode & $\begin{array}{c}\text { Standard } \\
\text { Deviation }\end{array}$ & $\begin{array}{c}\text { Sample } \\
\text { Variance }\end{array}$ \\
\hline Canyon River & 1.86 & 0 & 0 & 2.47 & 6.09 \\
Cascadia & 6.11 & 6 & 6 & 0.60 & 0.36 \\
Cascadia North & 5.08 & 5 & 5 & 0.27 & 0.07 \\
Lake Creek & 1.82 & 0 & 0 & 2.41 & 5.79 \\
Nisqually (h) & 5.48 & 5 & 5 & 0.66 & 0.43 \\
Nisqually & 5.87 & 6 & 6 & 1.03 & 1.05 \\
Olympia & 0.53 & 0 & 0 & 1.54 & 2.37 \\
SeaTac & 6.62 & 7 & 7 & 0.53 & 0.28 \\
Seattle & 6.71 & 7 & 7 & 1.09 & 1.18 \\
SWIF & 5.93 & 6 & 6 & 0.78 & 0.60 \\
SWIF Southeast & 5.50 & 5 & 5 & 0.56 & 0.32 \\
Tacoma & 5.93 & 6 & 5 & 1.27 & 1.60 \\
\hline
\end{tabular}

County-level MMI descriptive statistics by earthquake: King County

\begin{tabular}{lccccc}
\hline Earthquake & Mean & Median & Mode & $\begin{array}{c}\text { Standard } \\
\text { Deviation }\end{array}$ & $\begin{array}{c}\text { Sample } \\
\text { Variance }\end{array}$ \\
\hline Canyon River & 1.84 & 0 & 0 & 2.44 & 5.94 \\
Cascadia & 5.76 & 6 & 6 & 0.60 & 0.36 \\
Cascadia North & 4.73 & 5 & 5 & 0.50 & 0.25 \\
Lake Creek & 1.45 & 0 & 0 & 1.92 & 3.70 \\
Nisqually (h) & 5.35 & 5 & 5 & 0.66 & 0.43 \\
Nisqually & 5.52 & 6 & 6 & 0.90 & 0.82 \\
Olympia & 0.42 & 0 & 0 & 1.23 & 1.52 \\
SeaTac & 6.07 & 6 & 6 & 0.52 & 0.27 \\
Seattle & 6.47 & 6 & 7 & 1.08 & 1.16 \\
SWIF & 5.79 & 6 & 5 & 0.88 & 0.77 \\
SWIF Southeast & 5.35 & 5 & 5 & 0.60 & 0.36 \\
Tacoma & 5.70 & 6 & 5 & 1.31 & 1.72 \\
\hline
\end{tabular}


County-level MMI-grouped PGA descriptive statistics by earthquake: Thurston County

\begin{tabular}{lccccc}
\hline Earthquake & Mean & Median & Mode & $\begin{array}{c}\text { Standard } \\
\text { Deviation }\end{array}$ & $\begin{array}{c}\text { Sample } \\
\text { Variance }\end{array}$ \\
\hline Canyon River & 5.39 & 5 & 5 & 0.49 & 0.24 \\
Cascadia & 6.93 & 7 & 7 & 0.25 & 0.06 \\
Cascadia North & 6.20 & 6 & 6 & 0.40 & 0.16 \\
Lake Creek & 1.25 & 0 & 0 & 2.17 & 4.69 \\
Nisqually (h) & 6.23 & 6 & 6 & 0.42 & 0.18 \\
Nisqually & 7.00 & 7 & 7 & 0.00 & 0.00 \\
Olympia & 5.91 & 6 & 5 & 0.88 & 0.78 \\
SeaTac & 6.43 & 6 & 6 & 0.50 & 0.25 \\
Seattle & 5.20 & 5 & 5 & 0.40 & 0.16 \\
SWIF & 5.00 & 5 & 5 & 0.00 & 0.00 \\
SWIF Southeast & 5.00 & 5 & 5 & 0.00 & 0.00 \\
Tacoma & 5.38 & 5 & 5 & 0.49 & 0.24 \\
\hline
\end{tabular}

County-level MMI descriptive statistics by earthquake: Thurston County

\begin{tabular}{lccccc}
\hline Earthquake & Mean & Median & Mode & $\begin{array}{c}\text { Standard } \\
\text { Deviation }\end{array}$ & $\begin{array}{c}\text { Sample } \\
\text { Variance }\end{array}$ \\
\hline Canyon River & 5.14 & 5 & 5 & 0.60 & 0.36 \\
Cascadia & 6.77 & 7 & 7 & 0.47 & 0.22 \\
Cascadia North & 6.01 & 6 & 6 & 0.18 & 0.03 \\
Lake Creek & 1.00 & 0 & 0 & 1.73 & 3.00 \\
Nisqually (h) & 6.22 & 6 & 6 & 0.41 & 0.17 \\
Nisqually & 6.25 & 6 & 6 & 0.43 & 0.19 \\
Olympia & 5.27 & 5 & 5 & 0.80 & 0.63 \\
SeaTac & 5.93 & 6 & 6 & 0.44 & 0.19 \\
Seattle & 4.99 & 5 & 5 & 0.43 & 0.18 \\
SWIF & 4.12 & 4 & 4 & 0.32 & 0.11 \\
SWIF Southeast & 4.51 & 5 & 5 & 0.50 & 0.25 \\
Tacoma & 5.18 & 5 & 5 & 0.55 & 0.30 \\
\hline
\end{tabular}


Community-level MMI-grouped PGA descriptive statistics by earthquake: Seattle

\begin{tabular}{lccccc}
\hline Earthquake & Mean & Median & Mode & $\begin{array}{c}\text { Standard } \\
\text { Deviation }\end{array}$ & $\begin{array}{c}\text { Sample } \\
\text { Variance }\end{array}$ \\
\hline Canyon River & 5.14 & 5 & 5 & 0.35 & 0.12 \\
Cascadia & 6.85 & 7 & 7 & 0.36 & 0.13 \\
Cascadia North & 5.00 & 5 & 5 & 0.00 & 0.00 \\
Lake Creek & 5.00 & 5 & 5 & 0.00 & 0.00 \\
Nisqually (h) & 5.69 & 6 & 6 & 0.63 & 0.39 \\
Nisqually & 6.58 & 7 & 7 & 0.49 & 0.24 \\
Olympia & 1.70 & 0 & 0 & 2.37 & 5.61 \\
SeaTac & 7.00 & 7 & 7 & 0.00 & 0.00 \\
Seattle & 7.80 & 8 & 8 & 0.68 & 0.46 \\
SWIF & 6.45 & 6 & 6 & 0.50 & 0.25 \\
SWIF Southeast & 6.33 & 6 & 6 & 0.47 & 0.22 \\
Tacoma & 6.48 & 6 & 6 & 0.52 & 0.27 \\
\hline
\end{tabular}

Community-level MMI descriptive statistics by earthquake: Seattle

\begin{tabular}{lccccc}
\hline Earthquake & Mean & Median & Mode & $\begin{array}{c}\text { Standard } \\
\text { Deviation }\end{array}$ & $\begin{array}{c}\text { Sample } \\
\text { Variance }\end{array}$ \\
\hline Canyon River & 5.10 & 5 & 5 & 0.29 & 0.09 \\
Cascadia & 6.21 & 6 & 6 & 0.43 & 0.18 \\
Cascadia North & 5.00 & 5 & 5 & 0.00 & 0.00 \\
Lake Creek & 4.05 & 4 & 4 & 0.22 & 0.05 \\
Nisqually (h) & 5.43 & 5 & 5 & 0.60 & 0.35 \\
Nisqually & 6.13 & 6 & 6 & 0.33 & 0.11 \\
Olympia & 1.36 & 0 & 0 & 1.90 & 3.59 \\
SeaTac & 6.31 & 6 & 6 & 0.46 & 0.21 \\
Seattle & 7.63 & 8 & 8 & 0.48 & 0.23 \\
SWIF & 6.39 & 6 & 6 & 0.49 & 0.24 \\
SWIF Southeast & 6.24 & 6 & 6 & 0.45 & 0.20 \\
Tacoma & 6.29 & 6 & 6 & 0.47 & 0.22 \\
\hline
\end{tabular}


Community-level MMI-grouped PGA descriptive statistics by earthquake: Olympia

\begin{tabular}{lccccc}
\hline Earthquake & Mean & Median & Mode & $\begin{array}{c}\text { Standard } \\
\text { Deviation }\end{array}$ & $\begin{array}{c}\text { Sample } \\
\text { Variance }\end{array}$ \\
\hline Canyon River & 6.00 & 6 & 6 & 0.00 & 0.00 \\
Cascadia & 7.00 & 7 & 7 & 0.00 & 0.00 \\
Cascadia North & 6.00 & 6 & 6 & 0.00 & 0.00 \\
Lake Creek & 4.84 & 5 & 5 & 0.88 & 0.77 \\
Nisqually (h) & 6.51 & 7 & 7 & 0.50 & 0.25 \\
Nisqually & 7.00 & 7 & 7 & 0.00 & 0.00 \\
Olympia & 7.67 & 8 & 8 & 0.47 & 0.22 \\
SeaTac & 6.62 & 7 & 7 & 0.49 & 0.24 \\
Seattle & 5.90 & 6 & 6 & 0.29 & 0.09 \\
SWIF & 5.00 & 5 & 5 & 0.00 & 0.00 \\
SWIF Southeast & 5.00 & 5 & 5 & 0.00 & 0.00 \\
Tacoma & 6.00 & 6 & 6 & 0.00 & 0.00 \\
\hline
\end{tabular}

Community-level MMI descriptive statistics by earthquake: Olympia

\begin{tabular}{lccccc}
\hline Earthquake & Mean & Median & Mode & $\begin{array}{c}\text { Standard } \\
\text { Deviation }\end{array}$ & $\begin{array}{c}\text { Sample } \\
\text { Variance }\end{array}$ \\
\hline Canyon River & 5.94 & 6 & 6 & 0.24 & 0.06 \\
Cascadia & 7.00 & 7 & 7 & 0.00 & 0.00 \\
Cascadia North & 6.00 & 6 & 6 & 0.00 & 0.00 \\
Lake Creek & 3.87 & 4 & 4 & 0.70 & 0.49 \\
Nisqually (h) & 6.46 & 6 & 6 & 0.50 & 0.25 \\
Nisqually & 6.63 & 7 & 7 & 0.48 & 0.23 \\
Olympia & 6.98 & 7 & 7 & 0.12 & 0.02 \\
SeaTac & 6.03 & 6 & 6 & 0.18 & 0.03 \\
Seattle & 5.10 & 5 & 5 & 0.29 & 0.09 \\
SWIF & 4.21 & 4 & 4 & 0.40 & 0.16 \\
SWIF Southeast & 4.90 & 5 & 5 & 0.29 & 0.09 \\
Tacoma & 5.90 & 6 & 6 & 0.29 & 0.09 \\
\hline
\end{tabular}


Summary statistics for paired-samples t-tests

\begin{tabular}{lcc}
\hline Spatial Area & t-critical & $\begin{array}{c}\text { Degrees of } \\
\text { Freedon }\end{array}$ \\
\hline State & 1.960 & 1893 \\
King County & 1.977 & 263 \\
Thurston County & 1.990 & 91 \\
Seattle city & 1.973 & 437 \\
Olympia city & 1.999 & 62 \\
\hline
\end{tabular}

